\title{
ALLOCATION RULES WITH OUTSIDE OPTION IN COOPERATION GAMES WITH TIME-INCONSISTENCY
}

\author{
Harald D. Stein \\ Vilnius Gediminas Technical University, \\ Saulètekio al. 11, LT-10223 Vilnius, Lithuania \\ E-mail:hd.stein@web.de
}

Received 20 December 2008; accepted 15 December 2009

\begin{abstract}
In game theory agents have the possibility to make binding agreements. The agents are assumed to determine their strategies based on intended but bounded rationality. The field of strategic games provides the possibility to an agent to understand the optimality of his behaviour. In coalition and network games stability, Pareto-efficiency and fairness of agreements is investigated. The paper shows the relationship between the different fields of game theory in the case of 3 agents. On that basis it shows the ubiquity of time-inconsistency in dynamic setting due to bounded rationality, deception and environment changes. The paper explains why allocation rules like the Shapley-based Aumann-Drèze-value and the Myerson-value for coalition structures must be modified in dynamic setting in order to consider the influence of excluded agents, the outside option. An accordingly modified allocation rule is introduced and investigated. It is shown that the "Aumann-Drèze-value" and the "Myerson-value for coalition structures" remains relevant for the case that the switching of the partner is connected with high costs. It is shown through the example of enterprise cooperation in supply chains that low partner switching costs require the introduced allocation rule that considers the outside option.
\end{abstract}

Keywords: coalition games, network games, allocation rules, Myerson-value, time-inconsistency, outside option, supply chain cooperation.

Reference to this paper should be made as follows: Stein, H. D. 2010. Allocation rules with outside option in cooperation games with time-inconsistency, Journal of Business Economics and Management 11(1): 56-96.

\section{Introduction}

This paper addresses the question of the ubiquity of time-inconsistency in contract conclusion and the "outside options" of cooperation partners. Enterprises or generally economic agents who intend to form a cooperative relationship have to take into account in dynamic setting that

- circumstances (i.e. environment),

- the ability of contemplation and

- the availability of information might change. 
With a big enough change, it possibly becomes advantageous for a cooperation partner to break the contract and switch to a new partner that represents the "outside option".

The allocation rules propose certain allocations in accordance to efficiency and fairness criteria. They are part of coalition and network games where the stability of binding agreements is investigated. Allocation rules represent the anticipation of the negotiation result if all agents perfectly compete for their interests. If not all agents cooperate, "coalition structures" are formed. The most important allocation rules for coalition structures are the "Aumann-Drèze-value" and the "Myerson value for coalition structures" (generalizations of the famous Shapley-value for coalition structures). Both values equivalent in the case of 3 agents, when 2 agents cooperate and 1 agent is excluded. However, both values neglect the possible impact of the excluded agent on the allocation. By giving his own offer, the excluded agent represents the outside option. This becomes important in models with dynamic setting, if the excluded agent preserves his offer, and the costs of switching the cooperation partner are not too high. The allocation rule must then fulfil a stricter notion of stability where it is not required that the agreement is binding (in accordance to coalition and network formation in noncooperative games).

It is shown that an allocation rule where Myerson's "axiom of balanced contributions" (interpretation of symmetry) is modified fulfils these needs. Finally the applicability of the proposed allocation rule in comparison with the other listed rules is shown with a supply chain example.

The paper is structured as follows:

- Chapter 2 provides a definition of game theory and introduces the main fields "strategic games", "coalition games" and "network games".

- In chapter 3 an overview is given about the reasons why agents' rationality is bounded (despite of the intention to act rationally) and about the ubiquity of timeinconsistency of agreements.

- The chapters 4, 5 and 6 introduce "strategic games", "coalition games" and "network games" with 3 agents.

- In chapter 7 the allocation rule under consideration of the outside option is developed.

- In chapter 8 it is shown how the developed allocation rule can be applied in problems of supply chains if the switching of the cooperation partner is not too expensive.

\section{Definition and the fields of game theory}

The object of game theory (Holler, Illing 2000; Peldschus 2008, 2009; Turskis et al. 2009) is the analysis of strategic decision situations, i.e. of situations in which the result depends on the decisions of more than one decider in a way that the result cannot be determined independently from the decisions of the others (Ginevičius et al. 2007; Liaudanskiene et al. 2009; Sobotka and Rolak 2009; Ustinovichius et al. 2006). It is a normative economic theory where the agent (economic decider) is led to an optimal 
decision (Jakimavičius and Burinskienė 2009a, b; Mitkus and Trinkūnienè 2008; Zavadskas and Vaidogas 2008). He is aware of the interdependency and all consequences of all decisions, and tries to act in the best possible manner (Plebankiewicz 2009; Ulubeyli and Kazaz 2009). Interest conflicts and allocation problems are the typical issues (Brauers et al. 2007; Zavadskas et al. 2008a). Game theory provides a language with abstract and formal instruments in order to analyze and understand such situations (Ginevičius and Krivka 2008; Ginevičius and Podvezko 2008b; Peldschus and Zavadskas 2005; Podvezko 2008; Zavadskas and Turskis 2008).

\begin{tabular}{|c|c|c|}
\hline & $\begin{array}{l}\text { Strategic games (SG) } \\
\text { (non-cooperative games) }\end{array}$ & (Ch. 4) \\
\hline i & $\begin{array}{l}\text { Networks games (NG) } \\
\text { (restricted cooperative games) }\end{array}$ & (Ch. 6) \\
\hline $\begin{array}{l}1 \\
1 \\
1\end{array}$ & $\begin{array}{l}\text { Coalition games (CG) } \\
\text { (cooperative games) }\end{array}$ & (Ch. 5) \\
\hline & $\begin{array}{l}\text { Intended but bounded } \\
\text { rational behavior }\end{array}$ & (Ch. 3) \\
\hline
\end{tabular}

Fig. 1. Structure of main fields of game theory

In the more restrictive definition i.e. by Holler, Illing (2000), each agent is aware of the agents' interdependency and each one anticipates that all other agents are aware of that interdependency as well. However many approaches violate this narrow definition. In figure 1 the structure of the main fields of game theory is proposed, as it is understood in this paper.

The preceding definition claims that the agent (or in the strict case all agents are in accordance with the ideal of the rational decider ("homo economicus").

However due to

- the complexity of decisions,

- cognitive restrictions or the of lack of contemplation or

- incomplete information,

humans' rationality is bounded. That is why in modern game theory the rationality postulate is weakened to "intended rationality" (Simon 1994; Rubinstein 1998).

In the "strategic games" (or non-cooperative games) agents' strategies are explicitly analyzed. "Coalition games" (or cooperative games) delve into the problems of influence and dominance in cooperation relationships based on binding agreements. "Network games" (or restricted cooperative games) are the newest direction of game theory and a generalization of coalition games. Situations where communication is restricted can be analyzed. Despite of the different formalizations, the fields of game theory are very close to each other. Coalition games are a special case of network games and only have a separate formalization due to historical reasons. The strategic games seem to be separated very strongly (due to formalization), but each coalition or network game has an implicit strategic game (Zavadskas et al. 2008b). If agreements are not binding (or the costs of breaking the agreement are low), the concepts of coalition and network games are in general not relevant.

\section{Bounds on the "Homo economicus" principle and time-inconsistency}

The theory of choice in economics is only a small part of the general philosophical problem that deals with decision making (Ginevičius and Podvezko 2009; Ginevičius and Zubrecovas 2009; Podvezko 2009; Šelih et al. 2008; Zavadskas et al. 2009). The 
ideal of the rationally thinking and acting person, the "homo economicus", is predominant in the economic theories. Though this ideal is barely achievable, it represents the target-state for the normative approach. The figures $2 \mathrm{a}-2 \mathrm{c}$ list

- the characteristics of a rational decider $(2 a)$,

- typical problems in the connection with rationality (bounds on rationality, Rubinstein 1998): contemplation and information (2b),

- the ubiquity of time-inconsistency (2c).

\begin{tabular}{|l|}
\hline "Homo economicus": the rational decider \\
- Individual rationality: perfect problem understanding, \\
consideration of al consequences of decision \\
- Preference orders: axioms of completeness and \\
transitivity, ordinal scaling (if no further assumptions) \\
- Assumption of cardinal scaling in game theory: intensity \\
of preferences (monetary value) is known \\
- Aggregation of preferences: attempt of $\geq 2$ agents \\
to achieve Pareto-efficient (collectively rational) agreement
\end{tabular}

Fig. 2a. Bounds on rationality: "Homo economicus" - postulate of perfectly rational decider

\begin{tabular}{|l|l|}
\hline Problems with rationality: contemplation & (Ch. 3.2) \\
- Quantification: Assessment of values of relevant elements, \\
and recognition of the dependencies between elements \\
- Prospect theory: endowment effect, loss aversion, \\
refraining effect \\
- Myopia in dynamic setting: incapability of farsightedness \\
- Complexity problem: complexity classes of algorithms, \\
contemplation costs and possibilities of simplification \\
Problems with rationality: information \\
- Imperfect information: insecurity about other agents, \\
insecurity about environment
\end{tabular}

Fig. 2b. Bounds on rationality: problems of contemplation and information

\begin{tabular}{|l|}
\hline Time-inconsistency of agreements: \\
- Agreements becoming obsolete due to: \\
changing circumstances (preferences, environment, etc.) \\
improved contemplation, new information (learning) \\
obliviousness, imperfect recall (forgetting) \\
- Outside-option: impact of excluded players \\
on coalition agreement due to giving possibility \\
offonning alternative coalition
\end{tabular}

Fig. 2c. Bounds on rationality: ubiquity of time-inconsistency and outside options

\subsection{Characteristics of the "Homo economicus"}

According to the explicated definition of game theory, it must be distinguished between:

- Individual rationality of the regarded agent,

- Rationality of all agents as common knowledge (more restrictive but often assumed, e.g. for Nash equilibria). 
The "Homo economicus" postulate requires from the agent perfect individual rationality. This means particularly:

- Knowledge and understanding of the problem and its implications,

- Ability to optimize,

- Clear preferences.

- Indifference to logically equivalent descriptions of alternatives and choice sets.

The agent has to overview all consequences of his decisions perfectly and must understand what the best possible decisions are.

He must be able to give a preference order to all possible strategies and must not be influenced by different but equivalent descriptions of the problem. In order to recognize his preference order, the agent compares all alternatives pairwise (Güth 2007). A preference order is an n-tuple $\left(\omega, \omega^{\prime}, \ldots, \omega^{n}\right)$ from the set $\Omega^{n}$ and fulfils the axioms "completeness" and "transitivity":

- Completeness: the decision maker determines the preference relations for all pairs of alternatives,

- Transitivity: for the three elements $\omega, \omega^{\prime}, \omega^{\prime \prime} \in \Omega$ the following is fulfilled: if $\omega \succ \omega^{\prime}$ and $\omega^{\prime} \succ \omega^{\prime \prime}$ then $\omega \succ \omega^{\prime \prime}$.

E.g. a general preference order of an agent with 5 alternatives is of the form: $\omega \succ \omega^{\prime} \succ \omega^{\prime \prime} \succ \omega^{\prime \prime \prime} \succ \omega^{\prime \prime \prime \prime}$. So far nothing is said about the intensity of the preferences. Therefore in the general case only ordinal scaling (first, second, third, etc.) is justified. However models with ordinal preferences are connected with fundamental problems (Binmore 1994):

- Intractability: if an agent cannot recognize the exact value of his decision, complexity increases tremendously.

- General impossibility of preference aggregation (impossibility theorem, Condorcet 1785; Arrow 1970): it is generally impossible to find commonly accepted (no dictator) agreements for $\geq 2$ players and $\geq 3$ alternatives, if the preferences are ordinal, and the rationality requirement should be fulfilled.

Due to these problems, it is assumed that all agents exactly understand the monetary values of their decisions. Von Neumann and Morgenstern (2007) have determined cardinal preferences as the standard in game theory. Thus in opposite, the social choice theory attempts to deal with ordinal preferences.

The crucial criterion for preference aggregation in order to make an agreement is Pareto-efficiency (or Pareto-optimum, Pareto-dominance, collective rationality) that represents unanimity among the agents. If an allocation (e.g. distribution of goods among agents) is Pareto-efficient, no agent can be put into a better position, without worsening the position of another agent. That means that the total profit is distributed among the agents and nothing is left. If all agents participate, "welfare is maximized". However Pareto-efficiency can also refer to a subgroup of agents (component-Pareto-efficiency, link-Pareto-efficiency). In this case it is not welfare maximizing. Pareto-efficiency has no connection to fairness considerations. 


\subsection{Problems with rationality: contemplation}

Human decisions and behaviour are in general not perfectly rational. However this does not mean that they are chaotic. Simon (1994) introduced the distinction between substantive rationality and procedural rationality.

Substantive rationality means behaviour that "is appropriate to the achievement of given goals within the limits imposed by given conditions and constraints". Therefore all thinkable information and implications must be considered for strategy determination. Simon declares that substantive rationality is generally not achievable. In opposite, behaviour is procedurally rational if it is the outcome of appropriate deliberation. Roughly said, procedural rationality is the attempt to behave rationally. Impulsive decisions without intervention of thoughts are forbidden. Procedural rationality is also called intended rationality.

In connection with the bounded ability of contemplation, the following has to be considered:

- Quantification of factors, events or processes (Chen 2006),

- Problems of prospect theory,

- Myopia in dynamic setting,

- Problems of complexity (Rubinstein 1998).

It is often difficult to quantify, i.e. to count or measure relevant factors, events or processes (Brauers and Zavadskas 2006; Figuera and Greco 2005; Ginevičius and Podvezko 2008a; Ginevičius et al. 2006, 2008a, b; Liu 2009; Sivilevičius et al. 2008; Srnka and Koeszegi 2007; Šijanec Zavrl et al. 2009). The

- values of the relevant elements have to be assessed (Aumann 1970) and

- the dependencies between elements have to be identified.

The quantifiable components of a problem have to be separated from the non-quantifiable ones. In the best case it is possible to depict a problem perfectly in a formal way and quantify all elements on a cardinal scale (determination of monetary value). However if this is not possible, it must be assessed in the particular case in how far approximations lead to usable models and results.

The prospect theory of Kahneman and Tversky (1979) deals with systematic mistakes of human contemplation if not all information is known. These are typical mistakes that are approved by experiments:

- Overconfidence bias: people often overestimate their ability of understanding a situation and determining the right strategy,

- Endowment effect/loss aversion: people valuate thing higher if they possess them,

- Pseudo-certainty/reframing effect: people's decisions are often influenced by the way an uncertain situation is expressed.

Arieli (2008) has given new important contributions at the field of systematics of incorrect inferences, like the systematic human weakness to assess one's own willingness to pay and how it can exploited by smart negotiation. 
In dynamic setting, myopia is the incapability to understand and predict all future implications of one's own decisions (Dutta et al. 2004). Especially the stability of oneshot agreements might not be ensured if the game is dynamic. Connections between the agents may fall apart and other connections occur. The questions "Where will it all lead? Is the end result good or bad for me?" (Aumann and Myerson 1988) brings out the claim of farsightedness, i.e. the prerequisite of rationality in decisions with dynamic implications.

Complexity of problems restricts both the ability of humans and machines to make rational decisions. Particularly

- if the number of players increases,

- if information is incomplete,

- if players deceive,

- or the game is dynamic etc.,

complexity can increase tremendously. It is barely possible to measure the effort that an agent puts into contemplation. Therefore, in order to classify the complexity of game theoretic models, the approach of complexity classes of algorithms is borrowed from informatics. The most important complexity classes are (Steimle 2008; Nisan Roughgarden 2007):

- Polynomial-time algorithm (P-class),

- Non-polynomial-time algorithm (NP-complete class),

- Exceeding of NP-complete class (NP-hard class).

P-class problems are the easiest ones. There exists an algorithm that needs a number of calculation steps that can be expressed by a polynomial function, so that it can deal with big numbers. Problems of NP-complete class need an exponential function and therefore basically cannot deal with high numbers. Problems of NP-hard class are of that high complexity that it is not known whether there exists a general formula that estimates the computation steps. Usually, the finding of solutions in game theory is in the NP-complete class. In network games many problems are even in the complexity class NP-hard. However, the computer verification of an already found solution is mostly "just" in the simpler P-class.

If contemplation is connected with expenses, thinking about the problem becomes to a part of the problem in a broader sense. Then it is rational to simplify the problem. Problems of NP-complexity (exponential complexity growth) or NP-hardness (dubiety whether complexity is quantifiable) need simplification in the case of big numbers. Roughly said simplification can be reached by:

- implication (e.g. unification of agents to one representative),

- approximation (e.g. using of cardinal scaling).

Simplification in order to reduce complexity generally does not reduce the explanatory power of a model. Friedman (1966) argues that models can be useful even if they are based on wrong (or simplified) assumptions. Therefore models should be evaluated only with regard to the application. An example is ancient sea navigation that was based on earth-centred astronomy. Hence, incorrect assumptions are not necessarily a knock-out criterion in game theory. 


\subsection{Problems with rationality: information}

Game theory has various approaches that deal with insecurity. Agents have to understand consistently their own risk attitude when they face

- incomplete information about the moves and attitudes of other players (imperfect information),

- incomplete information about external factors or environment.

In the case of incomplete environment information, Harsanyi (1967) has proposed to depict nature, as if it was an agent. Games with incomplete information can be based on the formula of conditional probability of Bayes, if new information successively influences the decisions. However this is not the subject of this investigation.

\subsection{The time-inconsistency of agreements}

In dynamic setting circumstances steadily change, as the agents change their preferences and the exogenous factors (environment). Additionally, as rationality is restricted by contemplation and information problems, agents who intend to act rationally, stand in a permanent process of learning and forgetting. Learning can be understood as

- the improvement of contemplation or

- the reduction of incomplete information.

Obliviousness (or imperfect recall) can be regarded as an antagonistic force to learning or simply learning with negative sign. It is the inability to remember all obtained knowledge (Kuhn 1953).

These are some reasons why the time-inconsistency of agreements is ubiquitous. Therefore in dynamic setting the stability notion of solutions has to be refined. E.g. the net present value for breaking the contract can be compared with not breaking (Hellman 2008).

The outside option is the offer by an excluded agent to a participating agent to break an existing agreement in order to start a new one. As soon as it is advantageous, rational agents (single agents or groups) break the agreement (Casajus 2007). After Harsanyi (1977) the outside option can refer to agents:

- that are within the agreement group or

- that are partly within the group and partly outside.

In this paper only the case of 3 agents is regarded, where one agent is outside the cooperation and tries to "seduce" one of the 2 cooperating agents.

\section{Strategic games (non-cooperative game theory)}

Strategic games are covered by non-cooperative game theory. Though all fields of game theory are at least implicitly strategic, the non-cooperative game theory has its own formalization. Figure 3 gives an overview over strategic games. 
Strategy: complete determination of actions for

all situations based on available information

Strategies and strategic games:

(Ch. 4.1)

- Information: Depicted as matrices or tree diagram

- Function: information $\rightarrow$ action

Nash-equilibria and refinements:

- Nash-equilibrium: assumption of all agents' rationality

Stochastic games: mixed strategies

Sequential games: backward induction

- Dominant equilibrium: no assumption about other

agents' rationality

Network (special case: coalition) formation:

(Component-) Pareto-efficient Nash-equilibria:

- Coalition-proof Nash-equilibria

- Strong Nash-equilibria

Approval of coalition network formation:

- Coalitions: by all participating players

- Networks: by pairs of players

Fig. 3. Overview over strategic games

\subsection{Strategies and strategic games}

The strategy of agent $i, s_{i}$ is in the sense of game theory a function of the information set (all available information) $H_{i}$ on the action set $A_{i}$. Hence a strategy is defined as (Vega-Redondo 2003):

$s_{i}: H_{i} \rightarrow \mathrm{A}_{i}$ with $\forall h \in H_{i}$ and $s_{i}(h) \in A(h)$.

The information is depicted in matrices or a tree diagram with knots and relations. A strategy considers all possible outcomes for all thinkable situations, even if the probability of occurrence is expected as extremely low. All information has to be considered and an agent who intends to play rationally constructs a stringent decision model.

A strategic game is a 3-tuple consisting of the players $N$, the set of all possible strategy decisions $S_{i}$ and all possible outcomes $\pi_{i}$ (Vega-Redondo 2003):

$S G=\left\{N,\left\{S_{i}\right\}_{i=0}^{n},\left\{\pi_{i=1}^{n}\right\}\right\}$ with $s_{i} \in S_{i}$

\subsection{Nash-equilibria and refinements}

The Nash-equilibrium is a solution that has proven to be a fundamental concept in strategic games in order to find the right strategy. It results from the mutual anticipation that all other agents deploy optimal strategies and the rationality of all agents is "common knowledge". In the Nash equilibrium no agent has an incentive to deviate. The strategy choice is optimal because no agent can achieve higher outcome by deviating in consideration of the rational decisions of the other agents. Therefore the following infinite chain of statements is valid:

- every agent acts rationally,

- every agent knows that every agent acts rationally,

- every agent knows that every agent knows that every agent acts rationally,

- every agent ..., etc. 
A reaction function defines the assumed reaction of one agent on the assumed action of the other agents. The Nash-equilibrium is a fixed point of (set-valued) reaction functions formulated by Kukitani (1941). A fixed point is the intersection of a function with the identity $f(x)=x$. Therefore, if the argument of a reaction function is a Nash-equilibrium the result is the same Nash-equilibrium. Each agent selects an optimal strategy $s_{i}^{*}$ given the optimal strategies of all other agents. For agent $i$ the following must be fulfilled:

$u_{i}\left(s_{i}^{*}, s_{-i}^{*}\right) \geq u_{i}\left(s_{i}, s_{-i}^{*}\right) \forall s_{i}, s_{-i} \in S_{i}$.

In a stochastic game the agent does not select one alternative but he implements a lottery over several alternatives according to his knowledge about the probabilities. This is called a mixed strategy. In opposite, in a deterministic game he selects a pure strategy. Pure strategies can be regarded as special cases of mixed strategies, where only the probabilities 0 or 1 are allowed.

In a sequential game the agents face multi-stage decisions. At each stage the respective strategy is dependent on the information set about the future and the previous steps of the other agents. Sequential games are depicted in the form of a game tree. Important applications are:

- games with time dimension,

- games with more than two agents or imperfect nature information after Harsanyi, when one agent firstly has to wait for the decisions of others.

Then the Nash-equilibrium is determined by backward induction. That means that the sequential game is fragmented into sub-games and the equilibria are firstly determined for the chronologically last sub-games. Stepwise the equilibria are identified for the preceding steps until all sub-games are included. The resulting optimal strategy path is the Stackelberg Nash equilibrium.

The concept of dominant equilibria as the result of the iterated elimination of dominated strategies is very similar to the determination of the Nash-equilibrium. However the strict assumption that all other agents act rationally is dropped. Thus dominant equilibria are particularly relevant in games with bounded rationality. If an alternative is always disadvantageous independently to the decisions of the others, it is crossed off the list. The iteration is continued in the residual game. Thus for player $i$ the following is valid: $u_{i}\left(s_{i}^{*}, s_{-i}\right) \geq u_{i}\left(s_{i}, s_{-i}\right) \forall s_{i}, s_{-i} \in S_{i}$.

The results of the iteration are always Nash-equilibria but are rarer due to higher requirement (Harsanyi, Selten 1988), as shown in figure 4.

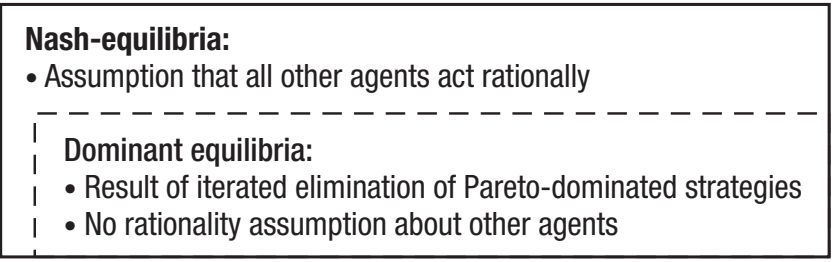

Fig. 4. Nash-equilibria and dominant equilibria as subset 


\subsection{Network formation and the special case of coalition formation}

Coalitions and networks can only be formed endogenously if they are mutually best strategies (Hart and Kurz 1983; Kahan and Rapoport 1984; Joshi 2006; Ray 2007; Sun et al. 2008). If one agent cannot force another one to "agree", the agreements must be self-enforcing. Self-enforceability means immunity to deviations by single agents or subcoalitions. Pareto-domination (= Pareto-efficiency) is the precondition for selfenforceability. The outcome cannot be dominated by other ones. Coalition or network formation is never unilateral. Networks are aggregations of bilateral links and therefore for each link the both participating agents have to agree. A coalition is a special case of a network where each agent is linked to each other one equally. Oppositely, in order to disband a coalition or network-link, only 1 participant needs to leave. This is shown in Table 1.

Table 1. Necessary agents to form or disband a coalition or network-link

\begin{tabular}{lll}
\hline & Coalition & Network-link \\
\hline Formation & $\geq 2$ agents & Exactly 2 agents \\
\hline Disbandment & $\geq 1$ agent & 1 or 2 agents \\
\hline
\end{tabular}

Traditionally, non-cooperative and (restricted) cooperative game theory is divided by the criterion of whether binding agreements are possible. However in dynamic setting this border often blurs. Agreements might be binding not more than over one or few rounds. There can be structural issues or contractual penalty that makes the exit from the coalition or network costly. The crucial question in coalition and network games is the stability of agreements (or the possibility of blocking agreements).

Regarding the difficulty of making binding agreements in the long run, two stability approaches of non-cooperative games become relevant in coalition and network games. Both are Pareto-efficient Nash-equilibria. They are relevant, if there is the possibility of forming a coalition or network with at least 3 agents:

- the strong Nash equilibrium,

- the coalition-proof Nash equilibrium.

Aumann (1959) defined the "strong Nash equilibria" (SNE) as follows: "An equilibrium is strong if no coalition, taking the actions of its complement as given, can cooperatively deviate in a way that benefits all of its members." In opposite to usual Nash equilibria, the strong Nash equilibrium regards the possible deviations of all conceivable coalitions instead of single agents. However that approach has two important weaknesses. Firstly, the criterion is too strict so that the SNE rarely occurs. Secondly, the subcoalitions that decide to leave the coalition do not care anymore about selfenforcement (and actually need a binding contract). Bernheim / Peleg call this "internal inconsistency". They define "internal consistency" as the judgment of the validity of deviations by the same criteria the original agreement is judged.

Therefore Bernheim and Peleg (1987), Bernheim and Whinston (1987) proposed the coalition-proof Nash-equilibrium (CPNE). They define: "An agreement is coalitionproof if and only if it is Pareto-efficient within the class of self-enforcing agreements. In 
turn, an agreement is self-enforcing if and only if no proper subset (coalition) of agents, taking the actions of its complements as fixed, can agree to deviate in a way that makes all of its members better off." In other words, a coalition-proof Nash-equilibrium cannot be attacked by a Pareto-superior subcoalition that cannot be attacked by Pareto-superior subcoalitions themselves. That means internal consistency. In comparison to the strong Nash-equilibrium it is less restrictive, because internal consistency of the deviating subcoalition is a restriction on the restriction as shown in figure 5.

\begin{tabular}{|c|c|c|c|}
\hline & $\begin{array}{ll}\text { Pareto-efficiency: } & N \geq 2 \\
\text { no Pareto-dominanceby other Nash-equilibria } & \end{array}$ \\
\hline$r$ & \multirow{2}{*}{\multicolumn{3}{|c|}{$\begin{array}{ll}\text { Coalition-proof Nash-equilibrium } & N \geq 3\end{array}$}} \\
\hline & & & \\
\hline 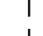 & \multicolumn{3}{|c|}{ nt (restriction is restricted, thus les } \\
\hline I & \multicolumn{3}{|c|}{ coincides: Pareto-efficiencv + dominant equilibrium } \\
\hline & & & \\
\hline & & tron & \\
\hline & & Ila & \\
\hline & & nconsistent (strict restriction) & \\
\hline
\end{tabular}

Fig. 5. Non-binding agreements: relationship of Pareto-efficient NE, strong and coalition-proof NE

The CPNE has properties that make it very interesting in the context of coalition and network formation:

- CPNE coincides with Pareto-efficient solutions that are dominant equilibria (Moreno and Wooders 1996),

- CPNE almost always exist (Moldovanu 1992).

CPNE cannot be Pareto-dominated and at the same time it is not demanded that the other agents act rationally. Nouweland (2003) argues that CPNE always exists if a game has the property that additional agents always bring additional profit (superadditivity). However though this demand is relatively weak, it is not always fulfilled either.

In the following chapters, the stability of binding agreements is only compared with the stability notion of coalition-proof Nash-equilibria (non-binding agreements).

\section{Coalition games (cooperative game theory)}

The main feature of cooperative game theory or coalition games is that binding agreements are made (Wiese 2005). The contracts the agents make are asserted by a higherranking institution, usually the state. Agents that are connected by contracts, form a "coalition". Coalitions do not eliminate the agents as individual decision makers but act as "representative agents" for the agents. Coalitions can be instances of institutions like supply chains, cartels, syndicates, trade unions, political parties, etc. However, they are ordinarily modelled in a neutral sense, without institutional implications. The fields of coalition games focused on the one hand on

- the possibility and

- the stability

of sets of allocations. On the other hand they focus on rules that determine the allocations exactly. In this paper the transferability of utility between the agents without losses 
is assumed (TU-games). Aumann (1961) defines the following preconditions for utility transferability:

- Utility is linear and divisible.

- There is an accepted medium (money) (Bergstrom and Varian 1985).

The generalized assumption of non-transferable utility leads to highly more complex games (NTU-games) but is not regarded in this paper.

A coalition game $C G=(N, v)$

contains a non-empty set of agents and a characteristic function $v$ that assigns outcomes to all possible coalitions (Wiese 2005). $v$ is a correspondence (set-valued function) between finite partly ordered sets (Peleg and Sudhölter 2003):

$v: \operatorname{Powerset}(N)=2^{N} \rightarrow \mathfrak{R}_{+}$.

Thus characteristic functions of three agents have the following structure:

$$
v(\text { Powerset }(3))=v(\{A\} ;\{B\} ;\{C\} ;\{A ; B\} ;\{A ; C\} ;\{B ; C\} ;\{A ; B ; C\}) \text {. }
$$

It is convenient and usual to normalize the outcomes of 1-agent-coalitions to 0 :

$$
v(\text { Powerset }(3))=v(0 ; 0 ; 0 ;\{A ; B\} ;\{A ; C\} ;\{B ; C\} ;\{A ; B ; C\}) \text {. }
$$

\begin{tabular}{|l|}
\hline Coalition: representative player as result of \\
binding agreement \\
Characteristic (coalition) function: \\
values of all subcoalitions (components) of $\mathrm{N}$ players: $2^{\mathrm{N}} \rightarrow \mathrm{R}$ \\
- Possible properties: superactivity, convexity, balancedness \\
- Imputation sets: individual rationality (IR), Pareto-efficiency (PE) \\
- Dynamic setting: problem of time-inconsistency of agreements \\
I Stability notions of coalitions and axiomatic allocation rules \\
\hline
\end{tabular}

Fig. 6a. Coalition games (with transferable utility): characteristic coalition functions

\begin{tabular}{|l|}
\hline Stability notions of coalitions and axiomatic allocation rules \\
\hline Not balanced characteristic function: \\
- Properties: grand coalition not stable, core does \\
not exist (empty), stable subcoalitions exist \\
- Allocation set: Maschler-Aumann-Bargaining set (Properties: \\
IR, component-PE, subcoalitions cannot block; outside option) \\
- Allocation rule: Aumann-Dreze-Value (Properties: \\
component-PE, balanced contributions, no outside option) \\
I Balanced characteristic function: (stable grand coal.) (Ch. 5.2) \\
- Allocation set: core (Properties: IR. PE. subcoalitions \\
influence but cannot block; power of all non-dummy agents) \\
- Allocation rule: Shapley-value (Properties: PE, \\
balanced contributions) \\
- If characteristic function convex, Shapley-Value \\
inside core
\end{tabular}

Fig. 6b. Coalition games (with transferable utility): stability notions, axiomatic allocation rules for balanced and non-balanced characteristic functions 
The figures $6 \mathrm{a}$ and $6 \mathrm{~b}$ give an overview of coalition games with the following issues:

- characteristic (coalition) functions (6a),

- games with balanced cores (6b),

- games with empty cores (6b).

As it is assumed in coalition and network games that higher-ranking institution assert the agreement (self-enforceability is not required), the stability notion is less strict than the non-cooperative games (CPNE, Aumann's strong equilibrium).

\subsection{Characteristic functions}

Characteristic functions capture the potential worth of each coalition or subcoalition of agents in a single numerical index. The values can be interpreted as the outcomes of optimal strategies of agents that make binding agreements. Therefore strategic games can be regarded as implicit in coalition games. The difficulties of the strategic interdependence or of the transactions themselves are separated or eliminated. In chess, for instance if the characteristic function would be known, it would simply state "white wins (value: 1)", "black wins (value: -1 )" or "draw (value: 0)". Therefore the characteristic function is a collection of pre-solutions.

In a coalition game not all agents necessarily cooperate. There can be concurrently several coalitions that together form a coalition structure CS (synonym: partition). In that case the single coalitions are subcoalitions (synonym: components). In the special case that all agents cooperate and the coalition-structure consists of one component it is called "grand coalition". Traditionally, in the coalition games, the components of a CS do not overlap and are non-empty. However, this assumption is not valid in the more general network games.

If a coalition game has a coalition structure with more than one subcoalition it is a proper $C S$. As the agents decide individually rational, the notion of Pareto-efficiency is modified to the more general "component-Pareto-efficiency". In the case of only 2 connected agents (bilateral) it is the "link-Pareto-efficiency". It means that Paretoefficiency is only achieved inside the subcoalition. In general individual rationality does not imply the wish of overall welfare.

The left Hasse-diagram (picture of a power set) in figure 7 depicts all possible subcoalitions for three agents in the form of a half-ordered closed combinatorial structure (Bilbao 2000). The right Hasse-diagram shows all possible and coalition-structures for three agents.

The rows in the both Hasse-diagrams in figure 7 are interpreted as follows:

- First row: the "grand coalition" is shown. All three agents appear at the market as one representative agent (monopoly, cartel, etc.). It is thinkable that a single agent or subcoalition blocks or raises an objection. The partition is of one component and is therefore not proper.

- Second row: on the left side all 2-person coalitions are shown. On the right side all three possible $\{2-1\}$-agent partitions are shown. As the partitions have two components they are proper. Each $\{2-1\}$ partition is possibly dominated by a grand coalition, blocked by a 2 -agent subcoalition or one agent out of the 2-agents'component. 


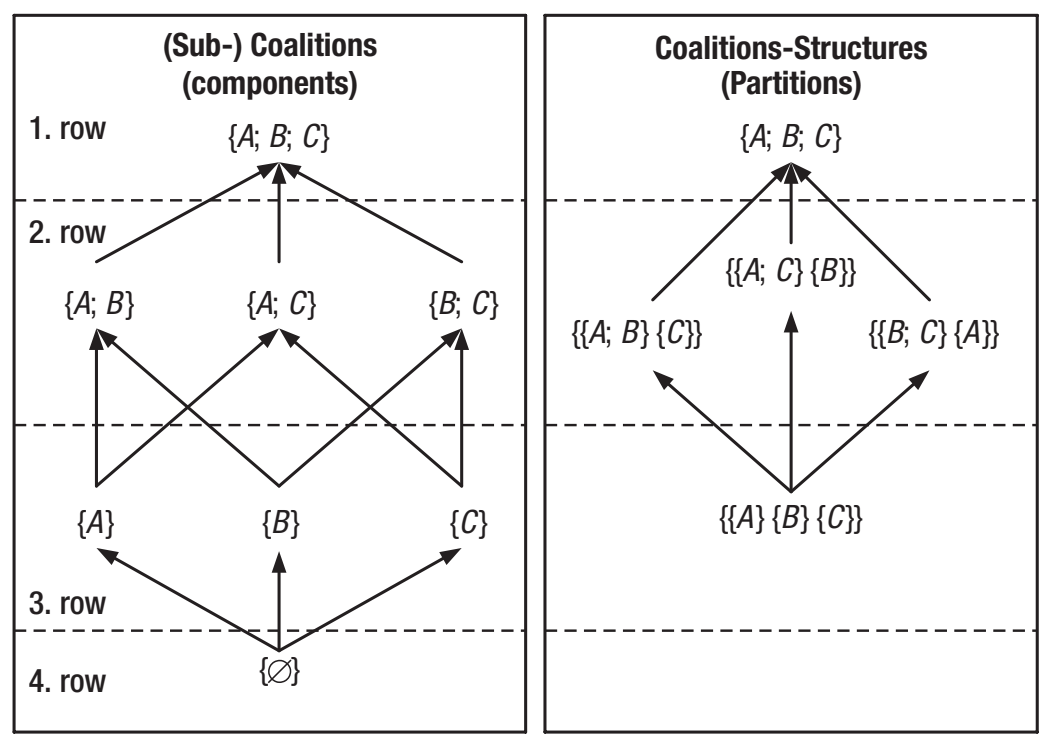

Fig. 7. Hasse-diagrams for 3 agents (left: all (sub-) coalitions; right: all coalition structures)

- Third row: these are "single-agent-coalitions" as the number of components equals the number of agents. Such a partition implies a strategic game without binding agreements.

- Lowest row: The empty set has the value 0 . There are no exceptions.

An imputation set (synonym: budget constraint) contains all Pareto-efficient allocations of a particular coalition. A characteristic function contains the values (total outcomes) of all possible coalitions or subcoalitions. Thus, imputation sets fulfil the minimal rules

- $\quad$ individual rationality,

- $\quad$ Pareto-efficiency.

An imputation set is formally:

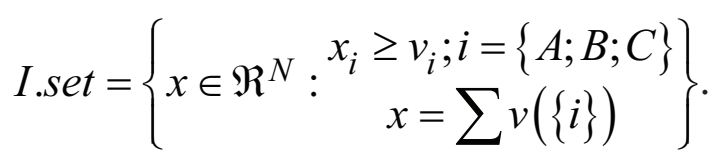

Geometrically, an imputation set is an (N-1)-dimensional simplex (N: number of agents). A simplex is an n-dimensional generalization of a triangle. For instance, 4 cooperating agents in a TU-game have an imputation set in the form of a tetrahedron ( 3 dimensions) in a 4-dimensional space.

Figure 8 shows examples with 3 agents (all variants with 2 agents are inclusive). The three lines under the triangle represent the respective budget constraints / imputation sets for the 2-agents coalitions $\{A ; B\},\{A ; C\},\{B ; C\}$. These lines (2-simplexes) are delimited by the axes due to the individual rationality (each agent obtains 0 without cooperation). In the case of 3 agents the imputation set is a triangle ( 3 -simplex in $\mathrm{R}^{3}$ ). That triangular 3-person imputation set is above the 32 -person imputation sets. This is because in this example all agents together can achieve more profit than two agents alone (superadditivity). At the edges, one of the three agents does not obtain anything from the profit. Furthermore, in the corners one agent obtains everything and the other two nothing. Usually this 3-persons imputation set is depicted as projection triangle, 


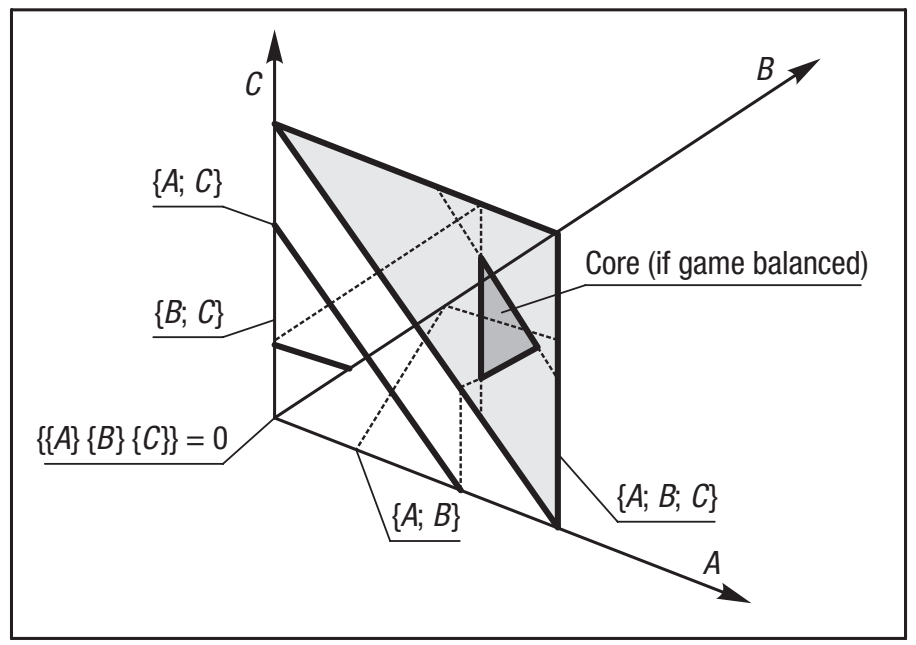

Fig. 8. Imputation sets of a superadditive and balanced characteristic function with 3 agents for all 2-agents' subcoalitions and the core (chapter 5.2)

where the origin of the coordinate system is exactly in the middle of the image, as shown in the next chapters.

Three important properties of characteristic functions in the context of dominance or blockings are:

- superadditivity,

- balancedness,

- convexity.

Superadditivity means that the total profit increases monotonously if new agents enter the coalition. The imputation sets in figure 9 result from a superadditive characteristic coalition function with 3 agents (because the triangle is above all 2-agents imputation sets). Formally expressed that means for all subcoalitions $R, S \subseteq N$, if the coalitions do not overlap:

$v(R)+v(S) \leq v(R \cup S)$.

Balancedness is crucial for the dominance of the "grand coalition" over the subcoalitions. The following relation ensures balancedness:

$v(N) \geq\left(\frac{1}{N-1}\right) \times \sum_{j=1}^{N} v(N \backslash j)$.

With a balanced characteristic function the "grand coalition" provides a higher value than the "sum of all coalitions where 1 agent is missing, divided by the number of these". Then it is possible to form a grand coalition in a way that it cannot be blocked by any subcoalition (or single agent). In characteristic functions with 2 agents balancedness is identical with superadditivity. In the case of 3 agents, superadditivity is implied. Balancedness has the following condition:

$$
v(A ; B ; C) \geq \frac{v(A ; B)+v(A ; C)+v(B ; C)}{2} \text {. }
$$


Convexity of a characteristic function means that the larger a coalition the higher is the marginal contribution of any entering agent. Convexity implies superadditivity but goes one step further (Topkis 1998). If a new agent enters the coalition, all agents in the coalition benefit. A coalition game $(N, v)$ is convex if for all (sub-) coalitions $S, S^{\prime}$ with $S \subseteq S^{\prime}$ the following is fulfilled:

$$
v(S \cup i)-v(S) \leq v\left(S^{\prime} \cup i\right)-v\left(S^{\prime}\right)
$$

In order to illustrate superadditivity, balancedness and convexity, four examples of characteristic functions are given:

$$
\begin{aligned}
& \text { 1. } v=(0 ; 0 ; 0 ; 40 ; 60 ; 50 ; 0) \\
& \text { 2. } v=(0 ; 0 ; 0 ; 40 ; 60 ; 50 ; 65) \\
& \text { 3. } v=(0 ; 0 ; 0 ; 40 ; 60 ; 50 ; 75) \\
& \text { 4. } v=(0 ; 0 ; 0 ; 40 ; 60 ; 50 ; 120)
\end{aligned}
$$

The characteristic function 1 is not superadditive because the "grand coalition" provides a profit of 0 . Therefore balancedness and convexity are disproved as well. Example 2 is superadditive, what means that the grand coalition provides the highest value. However as it is not balanced, the grand coalition is dominated by subcoalitions. Example 3 is superadditive and just balanced. Therefore there is exactly one profit distribution where the grand coalition cannot be dominated. Example 4 additionally fulfils convexity. Everyone has become better off by the entering of the last missing agent.

In convex characteristic functions network effects (or network externalities) occur. For instance, the more people use a technology, institution or standard (phones, industrial norms, virtual markets, etc.) the more utility arises for each single user.

Repeated coalition games are a sequence of static games whose value is determined by the (discounted) stream of payoffs. The characteristic function is time-separable, i.e. the agents are aware and are able to recognize their valuation of the game at any point of time. These are the sequences:

- sequence of characteristic functions:

$$
\left(v^{1}, \ldots, v^{T}\right)
$$

- sequence of coalition games:

$$
\left(C G^{1}\left(N, v^{1}\right), \ldots, C G^{T}\left(N, v^{T}\right)\right) \text {. }
$$

For instance, agents conclude a binding agreement in order to accumulate capital over several periods. Furthermore discounting can be considered after the principle of net present value (NPV).

If coalition games are repeated, the problem of time-inconsistency becomes important. Changing environment, bounded ability of contemplation and incomplete information cause permanent changes in preferences. The stability notion of CPNE is relevant, if the agreement is not perfectly binding. This paper restricts on time-inconsistency in games with non-balanced characteristic function so that there exists an excluded agent that represents the outside option. 


\subsection{Games with cores (balanced games): mutual influence in grand coalitions}

The core is the set of possible outcomes for a grand coalition that cannot be blocked by any other coalition or agent (Bhattacharya 2004; Kranich et al. 2005). It is the most important stability or dominance notion for grand coalitions (Jain and Vohra 2006). It is always a subset of an imputation set (as shown in figure 8) and therefore at least fulfils its rules "individual rationality" and "Pareto-efficiency". Additionally, as the Russian mathematician Bondavera (1963) and Shapley (1967) have shown, the core exists if and only of the characteristic function is balanced (Bondavera-Shapley-theorem). The core is defined as follows:

$$
\text { Core }=\left\{\begin{array}{cc}
\sum_{i \in S} x_{i} \geq v(S) \forall S \in 2^{N} \backslash\{\text { empty_set }\} \\
x \in \mathfrak{R}^{N}: \quad \begin{array}{c}
i \\
\end{array} \quad\{A ; B ; C\} \\
x=\sum v(\{i\})
\end{array}\right\} .
$$

Allocation rules provide or propose a certain distribution that fulfils certain criteria (axioms) like Pareto-efficiency or fairness (Holler and Owen 2001). Usually these values depend on the relative power of the agents. Therefore the total outcome of the game is compared with the total outcome it would have without the agent what is called the "added value" or the "contribution":

Added value/contribution of player $i=$ Value(coalition with $i)-V a l u e(c o a l i t i o n$ without $i)$

Power is also caused by threats. Then the "contribution" consists of not implementing the threat in comparison with implementing.

The most popular allocation rule in literature (Shapley 1953) that depicts relative power is the Shapley-value $S h$ (for grand coalitions). It assumes that the agents do not know ex ante in which order the grand coalition will be formed and that they are risk neutral. It is defined as follows:

$$
S h_{i}(v)=\sum_{S \subseteq N \backslash\{i\}} \frac{|S| !(n-|S|-1) !}{n !}[v(S \cup\{i\})-v(S)] .
$$

There are several equivalent axiom systems for the Shapley value. Two important systems are presented here. The first one is the original proposition by Lloyd Shapley, the second one by Roger Myerson. Shapley (Winter 2001) defines the axioms "Pareto-efficiency", "symmetry", "linearity" and "dummy agent". Pareto-efficiency determines that the complete outcome is distributed among the agents. Symmetry is the fairness condition that was firstly written down by Aristotle (Stanford Encyclopedia of Philosophy 2007). The relative outcome of each agent only depends on the relative contribution. Linearity assures the invariance to linear transformations and the dummy agent axiom determines that those agents who do not contribute anything to the common profit do not obtain anything of it. Only the Shapley-value exactly fulfils there requirements.

However there are other equivalent axiom systems that yield the Shapley-value. Roger Myerson has proposed a value for games with communication restrictions and has 
shown that the Shapley-value is a special case. His axiomatization of the Shapley-value has two requirements (Myerson 1980):

- Refinement of Pareto-efficiency: valid for $\mathrm{N}$ and all subsets of $\mathrm{N}$.

- Balanced contributions.

Thus in the case of 3 agents, not only the total outcome is distributed, but also the distribution among all pairs of agents is component-Pareto-efficient. The refined Paretoefficiency axiom is:

For all $S \subseteq N: \sum_{i \in N} S h_{i}(v)=v(S)$.

The axiom of balanced contributions means for the grand coalition or a subcoalition that the cutback of outcome for each agent is equal, independent from which agent exits. For all $S \subseteq N$ :

$$
S h_{i}(v(S))-S h_{i}(v(S \backslash\{j\}))=S h_{j}(v(S))-S h_{j}(v(S \backslash\{i\})) .
$$

For the stability (= non-blockability) of allocations that are determined by the Shapleyvalue it is important to distinguish whether the characteristic function is convex or not (Shapley 1971). If the characteristic function is

- convex: the Shapley-value lies inside the core,

- non-convex: it lies outside the core.

Therefore only with convex characteristic functions the Shapley-value proposes an allocation that cannot be blocked by subcoalitions.

Despite of the wide applicability the Shapley-value has its limitations. These are:

- It can be regarded as a recommendation for fair division. However it neglects the crucial questions of stability and dominance (that are covered by concepts like the core).

- Profit is only distributed among grand coalitions, when no subcoalition is able to block.

- It is calculated before the grand coalition started to form (ex ante value).

- It is assumed that the agents care about the order of coalition entrance, they do not know it and are risk neutral.

- In the original version the utility is transferable and the distributed good is homogeneous.

Now three examples are given to illustrate the relationship between the core and the Shapley-value in the case of balanced characteristic functions. These can be snapshots of a dynamic game where formerly made agreements become time-inconsistent:

$\left(G^{1}\left(N, v^{1}\right), G^{2}\left(N, v^{2}\right), G^{3}\left(N, v^{3}\right)\right)$

In figure $9 \mathrm{a}$ the characteristic function

$v^{1}=(0 ; 0 ; 0 ; 20 ; 15 ; 10 ; 30)$

is given. The last value 30 is the common profit that can be allocated with the restrictions of the imputation set. It determines the size of the triangle. A subcoalition $\{A ; B\}$ achieves 20, $\{A ; C\}$ achieves 15 and $\{B ; C\} 10$. In all points of the imputation set each 
agent contributes to the common profit. However at the edges the agent of the respective opposite corner is excluded from profit distribution/allocation. Therefore the edges represent the 3 possible (2-agents) subcoalitions. At the corners, one respective agent gains everything, and is therefore a dictator. The core contains all allocations that cannot be blocked by subcoalitions. However the lighter areas are not stable because they can be blocked.

The Shapley value proposes a "fair" division of the total profit into $(12.5 ; 7 ; 10.5)$ before the agents have started to enter the game. As the Shapley-value lies in the core, the game is convex and a stable and fair allocation is possible.

In figure $9 \mathrm{~b}$ the characteristic function

$$
v^{2}=(0 ; 0 ; 0 ; 20 ; 15 ; 10 ; 25)
$$

is depicted. The grand coalition profit is decreased to 25 . Therefore the imputation set triangle is smaller than in figure 9a. The core is relatively small because the agents $\mathrm{A}$ and $\mathrm{B}$ can almost achieve the grand coalition profit without $\mathrm{C}$. The function is not convex so that the Shapley-value lies outside the core. It can still be profitable all if $\mathrm{C}$ enters the $\{A ; B\}-$ subcoalition, but $\mathrm{C}$ cannot expect a "fair" solution (that is based on "balanced contributions", Shapley-value, etc.).

Figure 9c shows the characteristic function

$$
v^{3}=(0 ; 0 ; 0 ; 20 ; 15 ; 10 ; 20) \text {. }
$$

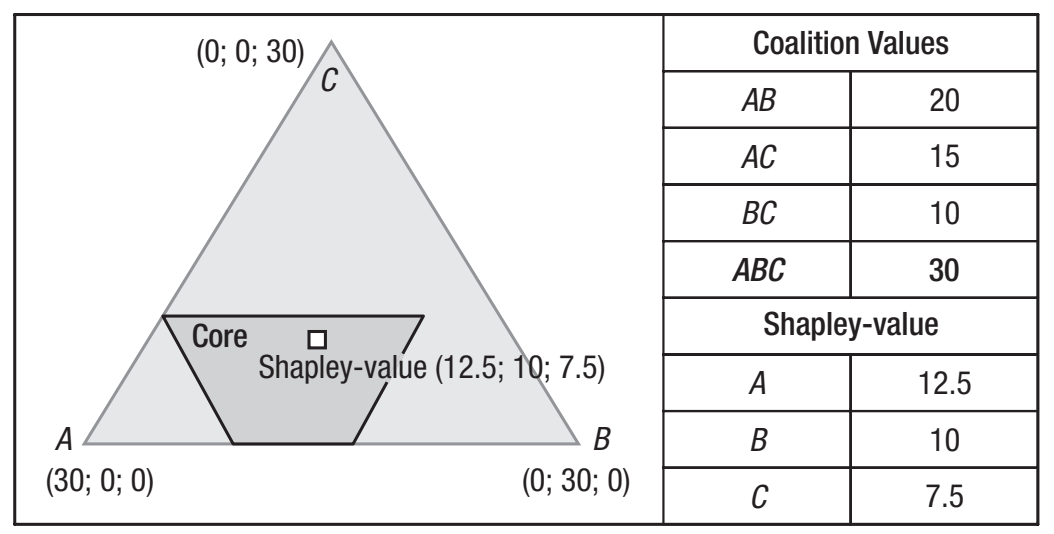

Fig. 9a. Balanced, convex characteristic function, Shapley-value inside the core

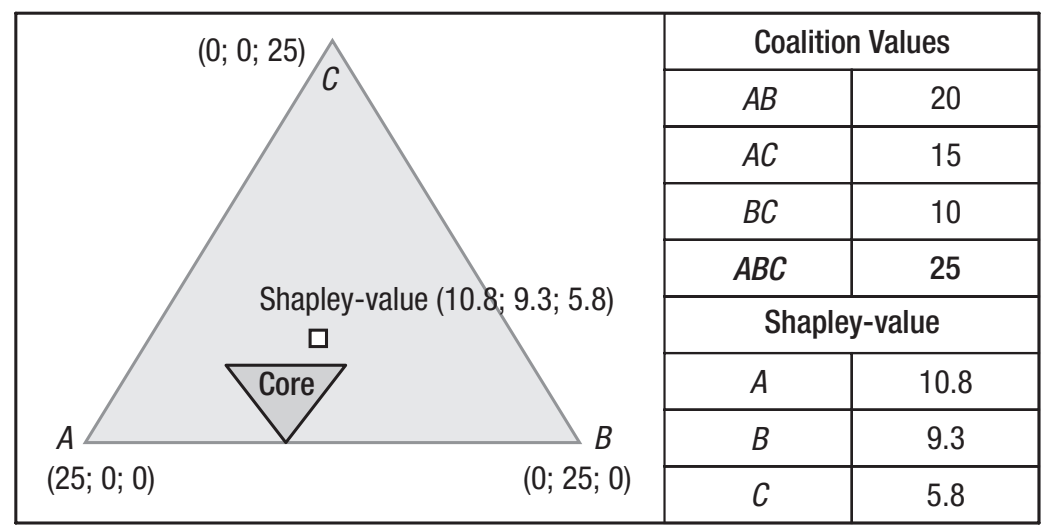

Fig. 9b. Balanced, non-convex characteristic function, Shapley-value outside the core 


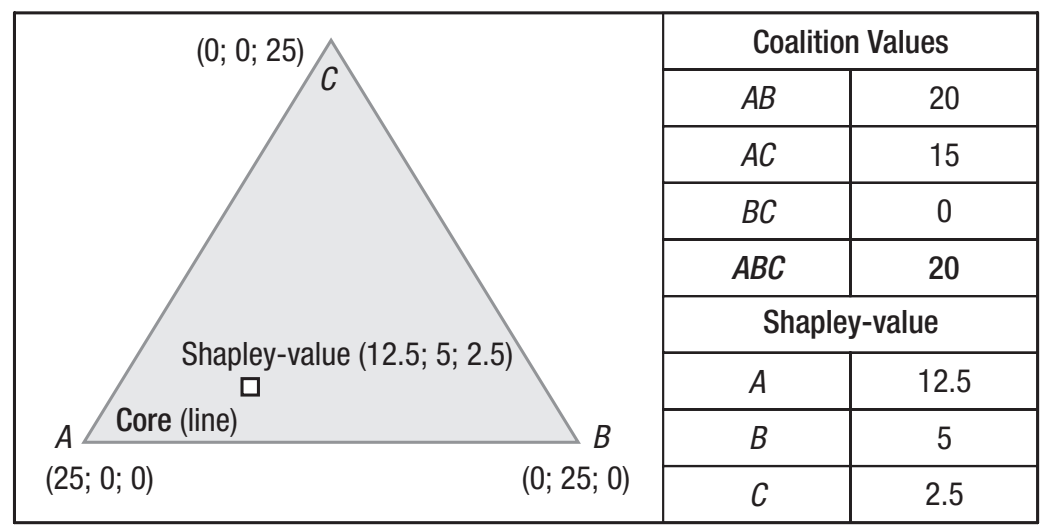

Fig. 9c. Balanced, non-convex characteristic function with edge-core, participation of

As the whole core is at the edge, all allocations inside the core are also stable for the subcoalition $\{A ; B\}$. However, only coalitions where agent $\mathrm{A}$ participates make profit. If there is already the subcoalition $\{A ; B\}, \mathrm{C}$ can join but neither brings harm nor utility, so that each attempt of $\mathrm{C}$ of participating in the profit division can be blocked. On the other hand if B claims a share that is $>5, \mathrm{C}$ can block it as well, so that despite of being "excluded", C has tremendous power on the allocation (outside option). Thus it is a peculiar case that the core or elements of the core lay at the edge, where it does not matter whether the grand coalition "officially" exists as it is equivalent to an according 2-agents-coalition ( 2 agents can make a stable agreement without officially leaving the grand coalition).

The change of the characteristic functions over the time leads to time-inconsistency of agreements. Both

- Stability, fairness and

- the bindingness of the agreement

are challenged. Hence, if the costs of breaking the agreement are "sufficiently low" the stricter notion of stability of non-cooperative games (i.e. CPNE) has to be investigated.

\subsection{Games with unbalanced characteristic function (empty core)}

If the core is empty, each grand coalition can be blocked by subcoalitions. Coalitional games with proper coalition structure come into the focus. Casajus and Tutic (2007) propose the partitional core (PCore), a generalization of the core for coalition structures. An important allocation rule for games with coalition structures is the AumannDrèze-value (AD-value) (Aumann and Drèze 1975).

An approach that is very close to the PCore and is well investigated, is the bargaining set $\boldsymbol{M}$ that was introduced by Maschler and Aumann (Davis and Maschler 1962; Aumann and Maschler 1964). It is a generalization of the core but provides information about the stability of payoff allocation if the core is empty. In the context of the bargaining set, a negotiation is described as a sequence of objections and counterobjections. It is regarded as a kind of stability when no objection (that is not neutralized by counter-objections) is made against an allocation. The objection can also be made by any subcoalition of agents so that concept of strong Nash equilibria is implicit in 
the bargaining set $\boldsymbol{M}$ (thus CPNE implicit as well). In the case of convex characteristic functions the core and the bargaining sets are identical (Peleg and Sudhölter 2003). The bargaining set $\mathcal{M}$ is the set of stable coalitionally rational payoff configurations with the

- payoff configuration: $(S, x)$ and

- coalitional rationality: $\sum_{i \in S} x_{i} \geq v(S)$ Sfor all $S \subseteq N$.

However, the disadvantage of all PCore approaches is that the does not exist any general solution algorithm yet, so that only particular problems can be analyzed in a structured way. Hence, in general it is not possible to state the complexity class of calculating a PCore. Only if it is specified in a way that the calculability is assured, complexity does not exceed NP-completeness.

The AD-value implements a Shapley-value like calculation within a "productive" (2-agents') subcoalition. In a coalition structure with 3 agents where A and B are productive $C S=\{\{A ; B\}\{C\}\}$, the profit is distributed component-Pareto-efficiently and in a balanced way (in this case equally) between $\mathrm{A}$ and $\mathrm{B}$. That means that for $\{A ; B\}$ as the productive component:

$\sum_{i \in\{A ; B\}} A D_{i}(v(\{A ; B\}))=v(\{A ; B\})$

is valid. Thus, the subcoalition profit is distributed as follows:

$$
A D=\left(\frac{v(\{A ; B\})}{2}, \frac{v(\{A ; B\})}{2}, 0\right)=\left(\frac{1}{2}, \frac{1}{2}, 0\right) \text { (normalized). }
$$

The AD-value is a generalization of the Shapley-value because in the case that the productive subcoalition is the grand coalition, both allocation values are identical.

In the following example with 3 characteristic functions (i.e. dynamic setting) the grand coalition is forbidden. With this restriction the problem is calculable. The bargaining set $\mathcal{M}$ is similar in this case with the edge-core of figure 9c. Figure 10a shows the characteristic function:

$v_{1}=(0 ; 0 ; 0 ; 20 ; 15 ; 0 ; 0)$.

If the partition $\{\{A ; C\}\{B\}\}$ is formed, firstly all payoffs that fulfil $\left(\{A ; C\} ;\left(x_{A}, \circ, 15-x_{A}\right)\right)$ with $x_{A} \in[0 ; 15]$, are candidates for an agreement between $\mathrm{A}$ and $\mathrm{C}$. However the agents $\mathrm{A}$ and $\mathrm{B}$ can bring the objection (that cannot be countered):

$\left(\{A ; B\} ;\left(x_{A}, 20-x_{A}, \circ\right)\right)$ with $x_{A} \in[0 ; 20]$. Therefore no coalition between $\mathrm{A}$ and $\mathrm{C}$ is stable in the sense of the bargaining set. If the partition $\{\{A ; B\}\{C\}\}$ is formed, the candidates for an agreement between $\mathrm{A}$ and $\mathrm{B}$ are:

$\left(\{A ; B\} ;\left(x_{A}, 20-x_{A}, \circ\right)\right)$ with $x_{A} \in[0 ; 20]$.

The agents $\mathrm{A}$ and $\mathrm{C}$ can only bring the objection (that cannot be countered):

$\left(\{A ; C\} ;\left(x_{A}, \circ, 15-x_{A}\right)\right)$ with $x_{A} \in[0 ; 15]$.

Thus the remaining $\boldsymbol{M}$-bargaining set is:

$\left(\{A ; B\} ;\left(x_{A}, 20-x_{A}, \circ\right)\right)$ with $x_{A} \in[15 ; 20]$. 
Figure 10b shows the characteristic function

$v_{2}=(0 ; 0 ; 0 ; 20 ; 20 ; 0 ; 0)$, and figure $10 \mathrm{c}$ shows

$v_{3}=(0 ; 0 ; 0 ; 20 ; 40 ; 0 ; 0)$.

In the case of $v_{2}, \mathrm{~B}$ and $\mathrm{C}$ give $\mathrm{A}$ the same proposal. $\mathrm{B}$ and $\mathrm{C}$ bid against each other till A gains the complete profit. In $v_{2} \mathrm{C}$ has the better proposal, but the possible outcomes are influenced by B.

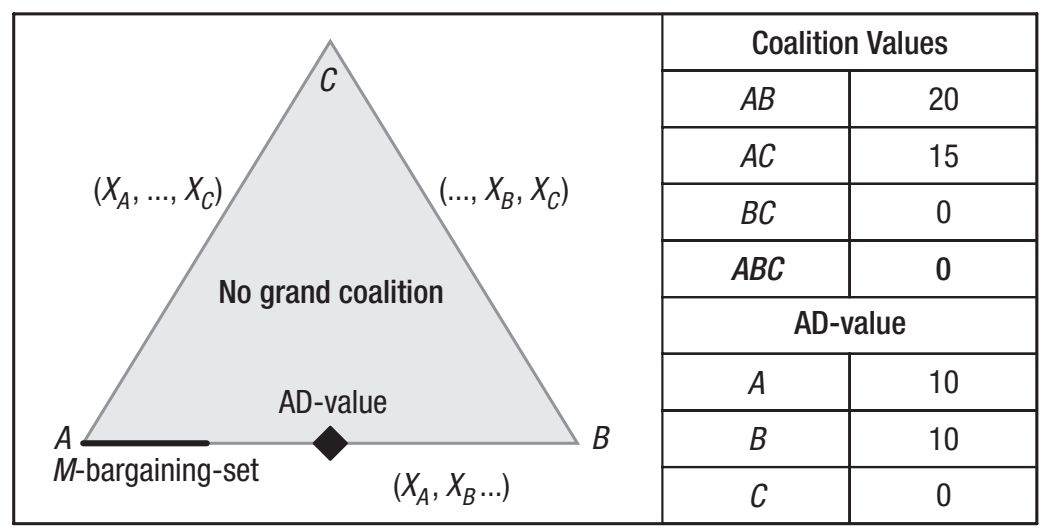

Fig. 10a. Bargaining set $\mathcal{M}$ (grand coalition prohibited), AD-value not stable against blocking by $\{B ; C\}$-coalition

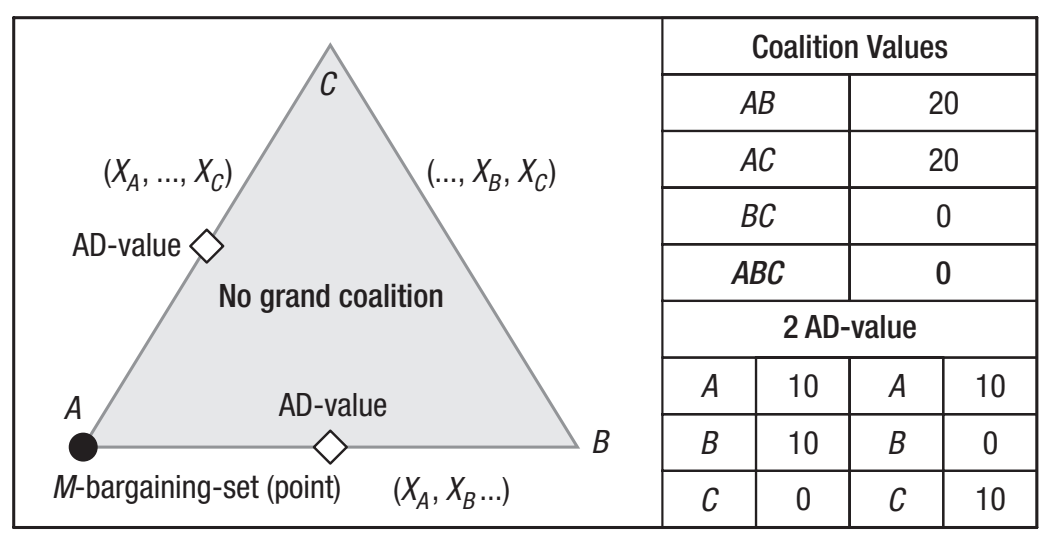

Fig. 10b. Bargaining set $\mathcal{M}$ (grand coalition prohibited), $\mathrm{B}$ and $\mathrm{C}$ of equal power, 2 AD-values that are both not stable

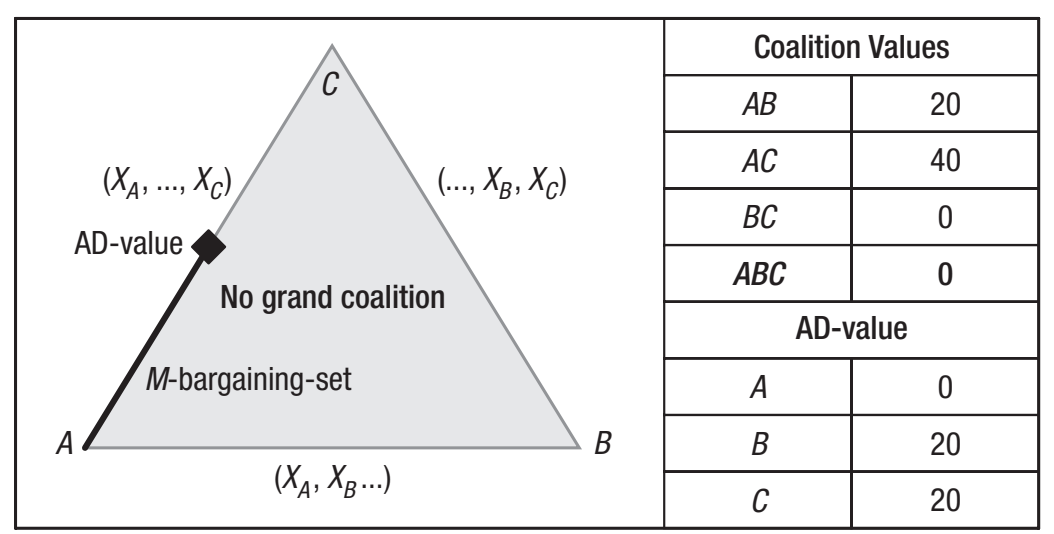

Fig. 10c. Bargaining set $\boldsymbol{M}$ (grand coalition prohibited), with stable $\mathrm{AD}$-value 
The bargaining set with prohibited grand coalition considers the outside option because it is influenced by the excluded agent. Allocations inside the bargaining set also are stable in the sense of CPNE. Due to the fact that the AD-value generally is not part of the bargaining set $\mathcal{M}$, it does not fulfil the notion of stability that is claimed in this paper for models with dynamic setting. The proposed allocation rule is a modification of the AD-value.

\section{Network games}

In coalition games it is the classical hypothesis that all coalitions of agents are possible without restrictions and the intensities of the connections are identical. However, that is a simplification that often is not justifiable. The formation of coalitions might be restricted due to structural issues, laws, culture ideology, etc. For instance one agent can be a business partner of two agents. However these two other agents are not connected among each other. This generalization leads to the field of "restricted cooperative game theory" or "network games", introduced by Myerson (1976), Aumann and Myerson (1988).

Network games $N G=(N, v, g)$ are based on non-directed graphs where bilateral links between the agents are united to networks. In the dynamic setting it is:

$N G^{1}=\left(N, v^{1}, g\right), \ldots, N G^{T}=\left(N, v^{T}, g\right)$.

As shown in Table 2 the number of possible subnetworks $g$ (excluding the empty network) for $N$ agents is $2^{N-1}$. Therefore it is identical with the number of possible subcoalitions.

Table 2. All possible networks with 3 agents based on bilateral links

\begin{tabular}{cccc}
\hline Agents & \multicolumn{2}{c}{ (Sub-) networks g } \\
\hline 3 & $\{\{A B\}\{A C\}\{B C\}\}$ (coalition game) \\
\cline { 2 - 4 } & $\{\{A B\}\{A C\}\}$ & $\{\{A B\}\{B C\}\}$ & $\{\{A C\}\{B C\}\}$ \\
\hline 2 & $\{A B\}$ & $\{A C\}$ & $\{B C\}$ \\
\hline
\end{tabular}

Coalition games are the special case where all agents are connected with each other, i.e. coalitions are networks with $\frac{n(n-1)}{2}$ links for $N$ agents (in Table 2: 3 bilateral links with 3 agents). Restrictions are the crucial feature of network games. In order to describe a network, it is necessary to define

- the characteristic (network) function and

- the restrictions

The information about the restriction is usually given by the maximally formable network (here: max-network). For instance, if the connection between $B$ and $C$ is forbidden, the "max-network" is: $g=\{A B, A C\}$.

The matriod in figure 11 depicts that such a restriction has tremendous impact on the 
possibilities of network formation. The rows of the matroid represent the numbers of bilateral links. In the

- 1. row: there are 3 links, all agents are connected with each other, grand coalition $(\mathrm{S}=\mathrm{N})$, corresponds to a typical coalition game.

- 2. Row: only the 2-link network $\{\{A B\}\{A C\}\}$ is possible, if all agents are involved.

- 3. row: $\{A B\}$ and $\{A C\}$ are possible, corresponds to subcoalitions.

- 4. row: empty network, the game is purely non-cooperative.

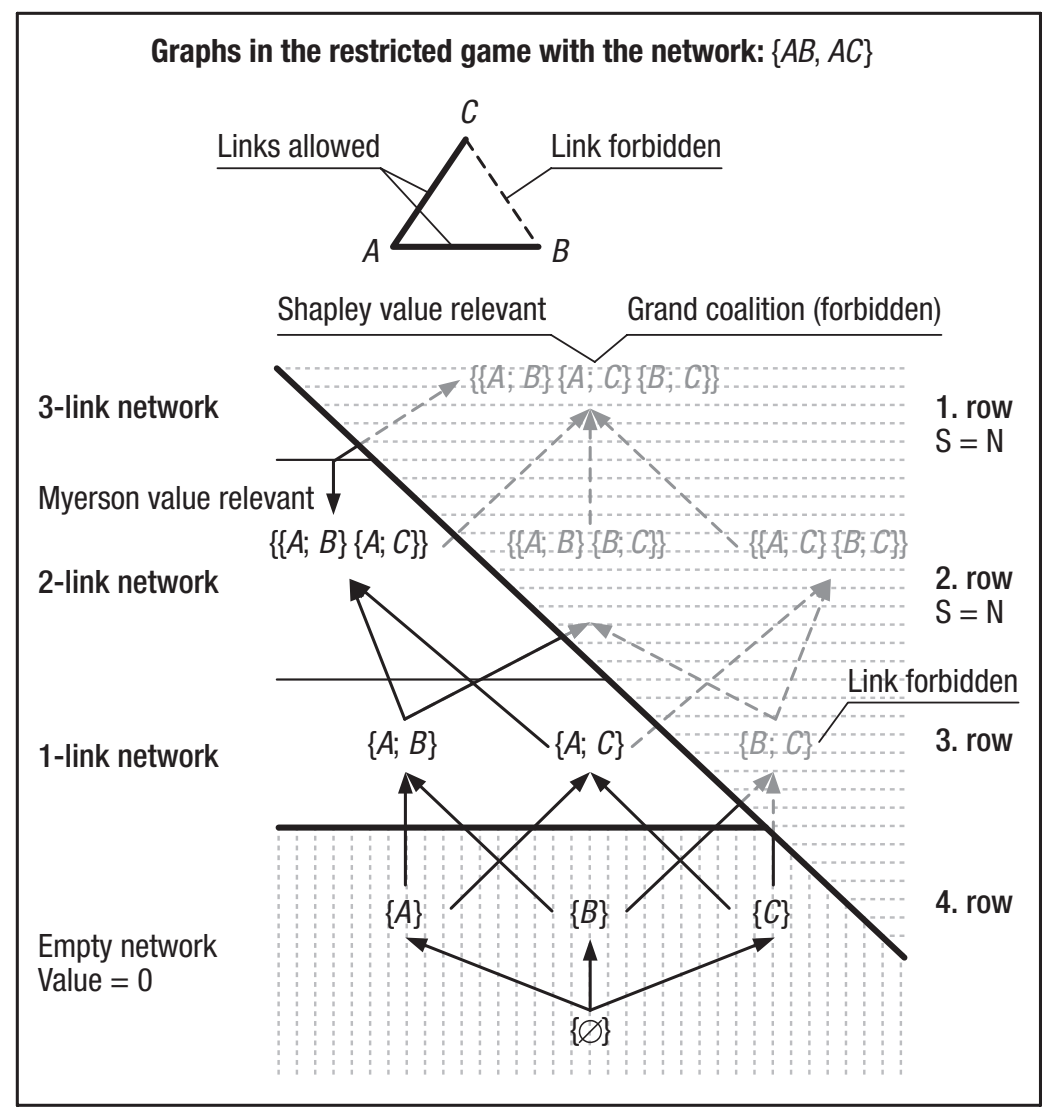

Fig. 11. Impact of restriction on possible networks with $g=\{A B, A C\}$

Thus, network games have the possibility of depicting the interaction between 3 agents much more precisely than the (traditional) coalition games. However this precision is bought by tremendously higher computational complexity. Many concepts of network games are deep in the complexity class "NP-hard" (Pin 2005).

Basically, all concepts of coalition games can be generalized to network games. However, that field is in its pioneer phase, literature is still sparse and fragmentary. Recent development has been triggered by Jackson (2003a, b), Bilbao (2000), Jackson and Nouweland (2003), Demange and Wooders (2005). Just in 2008, a generalization of the concept of the core (Zhao 2008) has been proposed. Such contemporary contributions can be regarded as introductory and exemplify the immaturity of network games.

Figure 12 shows the approaches of network games classified by the property of balancedness of the characteristic network function. Therefore it is furthermore assumed that utility is transferable. 


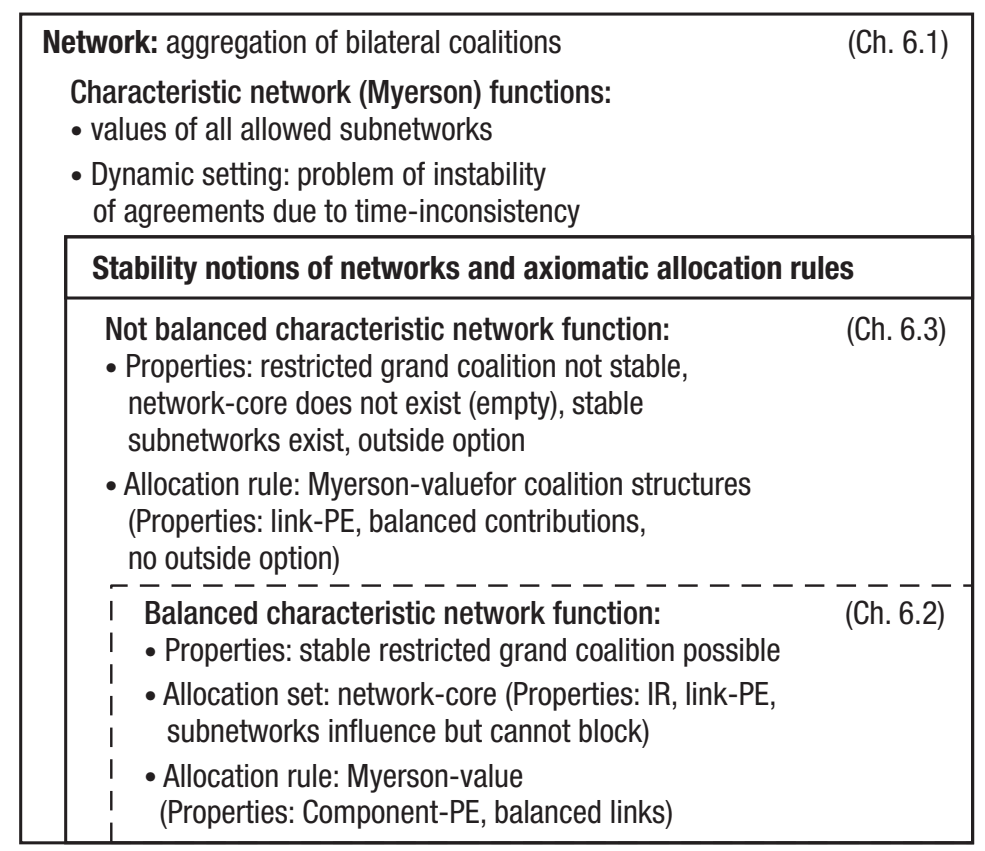

Fig. 12. Approaches of network games as generalization of coalition games (with transferable utility)

\subsection{Characteristic network functions (Myerson functions)}

The characteristic network functions (Myerson functions) define the values of all possible networks and are determined by the single bilateral links with $g_{S}$ and an arbitrary network with $S \subseteq N$ agents:

$$
v^{g_{s}}=\sum_{\text {link } \in g_{s}} v(\text { link }) \text {. }
$$

In a characteristic network function, each possible (sub-) network obtains a value. Due to the enormous amount of possibilities and the tremendous complexity, this paper restricts on the example of characteristic network functions with 3 agents and 1 forbidden link (here between the agents B and C). This is an example of a balanced characteristic network function:

$$
v_{c h .6 .1}^{g}=\left\{\begin{array}{l}
0 ;|S| \leq 1 \\
60 ; g=\{A B\} \\
40 ; g=\{A C\} \\
80 ; g=\{A B, A C\}
\end{array}\right. \text {. }
$$

\subsection{Restricted grand coalitions: balancedness and Myerson-value as allocation rule}

As in the coalition games, balancedness is the precondition for the stability of the biggest possible network with restrictions, the restricted grand coalition. The referring stability approach is the "network-core" (Zhao 2008) that is a core with restrictions, (very similar alternative: "pairwise stable network", Jackson and Nouweland 2003). An 
allocation in the network-core is stable because it cannot be blocked by subnetworks (or single bilateral links). The network-core is a generalization of the core in ordinary coalition games and has the properties (not an axiom system):

- Individual rationality.

- Component-Pareto-efficiency.

- Influence by all players.

Whether the characteristic network function is balanced, depends on the value of $g_{\max }=\{A B, A C\}$. The question is: What is the minimal value of $g_{\max }$, so that there exists an allocation that is not blockable by 2 agents through a single link? In the case of 3 agents and 2 links, Bondavera/Shapley's formula is valid:

$$
v(N) \geq\left(\frac{v^{\{A B\}}+v^{\{A C\}}}{2}\right) \text {. }
$$

Figure 13 shows, how in the case of $v^{\{A ; B\}}=60$ and $v^{\{A ; C\}}=40$, the balancedness is asserted with $v\{\{A ; B\}\{A ; C\}\} \geq 50$.

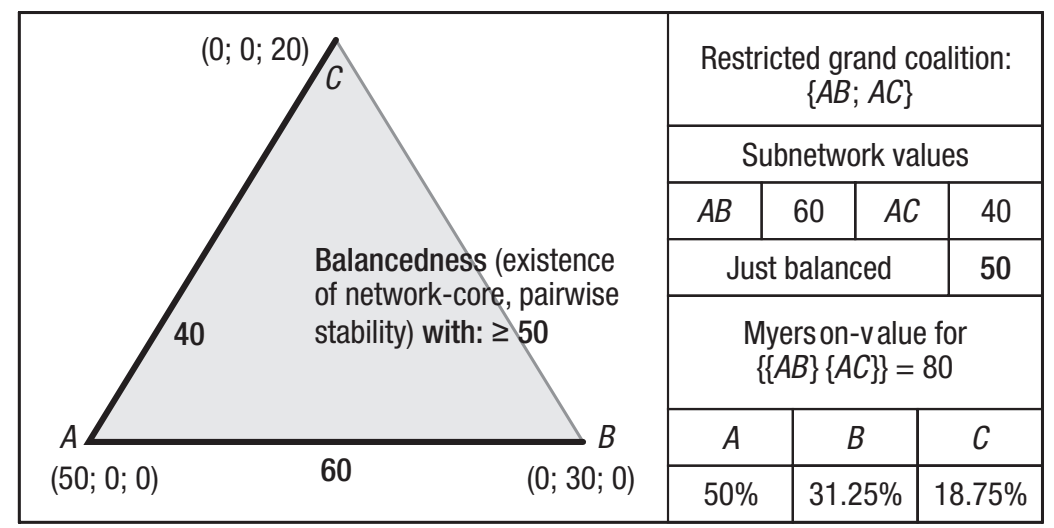

Fig. 13. Bilateral links and pairwise stability of the network with number example

The allocation rule for restricted grand coalitions is the Myerson-value (Navarro and Perea 2005; Pin 2005; Kajii et al. 2008) that is a generalization of the Shapley-value. Instead of subcoalitions that form the grand coalition stepwise, subnetworks form the restricted grand coalition stepwise. In figure 13, there are 2 paths that lead to the "maxnetwork":

$$
g^{\{A B\}} \rightarrow g^{\{\{A B\}\{A C\}\}} ; g^{\{A C\}} \rightarrow g^{\{\{A B\}\{A C\}\}}
$$

The Myerson-value is the expected value of the contribution, which the single agent gives, if it is not known yet, in which order the restricted grand coalition is going to be formed:

$$
M y_{i}(v)=\sum_{S \subseteq N \backslash\{i\}} \frac{|S| !(n-|S|-1) !}{n !}\left[v\left(g_{S \cup\{i\}}\right)-v\left(g_{S}\right)\right] .
$$

Myerson's original axiom system is: 
- Component-Pareto-efficiency for each link:

$\sum_{i \in C} M y_{i}(N, v, g)=v(C)$ for each link,

- axiom of pairwise balanced contributions:

$$
M y_{i}(N, v, g)-M y_{i}(N, v, g \backslash\{j\})=M y_{j}(N, v, g)-M y_{j}(N, v, g \backslash\{i\}) .
$$

These two axioms can only be fulfilled by the given formula for the Myerson-value. For the characteristic network function $v_{c h .6 .1}$ the Myerson-value for the 3 agents is: $M y_{A B ; A C}=(50 \%, 31.25 \%, 18.25 \%)$.

\subsection{Non-balanced characteristic network functions}

Non-balanced characteristic networks functions lead to a generalization of the idea of coalition structures to restricted cooperative games. The restricted grand coalition can be blocked by subnetworks that are restricted subcoalitions. However due to the fact that

- individual rationality and

- component-Pareto-efficiency

are the preconditions for stability on the subnetworks, a generalization of the PCore (i.e. bargaining sets) to network games is possible. However this problem is not solved yet. The approach of pairwise stability (Jackson and Nouweland 2003) leads into this direction.

The allocation rule is the Myerson-value for the coalition structures. In order to distinguish it from the Myerson-value for restricted grand coalitions, it is called in this paper Myerson-CS-value (It must not be confused with the CS-value for a-priori unions by Owen (Holler and Owen 2001) that is not relevant in the paper). If the subcoalition is unrestricted, it coincides with the AD-value. Taking the characteristic network function of chapter 6.1, the both Myerson-CS-values are:

$$
\begin{aligned}
& \text { Myerson } C S_{A B}=A D_{A B}=(30,30,0) \\
& \text { Myerson } C S_{A C}=A D_{A C}=(20,0,20) .
\end{aligned}
$$

Non-balancedness requires: $v\{\{A ; B\}\{A ; C\}\}<50$

Figure 14 depicts the relevance of the allocation rules for particular networks. The preceding chapters have shown that the Shapley-value refers to the network without restrictions and the Myerson-value refers to a network, where all agents participate, but there is a restriction. In opposite, the AD-value that equals to the Myerson-CS-value (with 3 agents), refers to a situation where there is only one link, and one agent is excluded. However the excluded agent does not have any influence on the allocation. Therefore the AD-value and the Myerson-CS-value neglect the outside option. 


\begin{tabular}{|c|c|c|c|}
\hline Relevant allocation & \multicolumn{3}{|c|}{ Possible networks with 3 agents } \\
\hline Shapley & & & \\
\hline Links: 3 / 3 & & $\mathrm{~g}=\{A B ; B C ; A C\}$ & \\
\hline Myerson & \multirow[b]{2}{*}{$\mathrm{g}=\{A B ; A C\}$} & \multirow[b]{2}{*}{$\mathrm{g}=\{A B ; B C\}$} & \multirow[b]{2}{*}{$\mathrm{g}=\{A C ; B C\}$} \\
\hline Links: 2 / 3 & & & \\
\hline $\begin{array}{l}\mathrm{AD}=\text { Myerson-CS } \\
\text { (outside-option } \\
\text { neglected) }\end{array}$ & \multirow[b]{2}{*}{$\mathrm{g}=\{A B\}$} & \multirow[b]{2}{*}{$\mathrm{g}=\{A C\}$} & \multirow[b]{2}{*}{$\mathrm{g}=\{B C\}$} \\
\hline Links: 1 / 3 & & & \\
\hline $\begin{array}{l}\text { No rule } \\
\text { (no binding } \\
\text { agreements) }\end{array}$ & & & \\
\hline Links: 0 & & $g=\{\varnothing\}$ & \\
\hline
\end{tabular}

Fig. 14. Relevant allocation rules and number of links of all possible networks with 3 agents

\section{Development of an allocation rule for coalition structures with outside option}

Due to the problem of time-inconsistency, the applicability of the Myerson-CS-value / $\mathrm{AD}$-value is restricted to cases where the cooperation is determined and stable over the complete duration. Due to high switching costs, no agent has the possibility to break the agreement advantageously. In order to consider the opposite case of low switching costs, an allocation rule is developed that considers the outside option. Table 3 depicts all sets of stable allocations (based on the core) and allocation rules that were introduced in this paper regarding the question of the outside option. It shows that the outside option is only relevant for non-balanced games.

An outside-option-modified allocation rule for coalition structures (here: OOCS-value) with the consideration of the outside option is proposed with the following axioms:

\section{- Component-efficiency:}

$\sum_{i \in C} \operatorname{OOCS}(N, v, g)=v(C)$ for the productive component

\section{- Modified axiom of balanced contributions}

The modification of the axiom of balanced contributions consists of a pre-stage, where the winning cooperation partner transfers the value of the loosing cooperation partner to the main agent. This coincides with the second-bid-auction of Vickrey (1961). Afterwards the balanced contributions axiom is used in the usual way. Thus: 
Table 3. Relationship of sets of stable allocations, allocation rules, outside option

\begin{tabular}{|c|c|c|}
\hline & Sets of stable allocations & Allocation rules (values) \\
\hline \multirow[t]{2}{*}{ Grand coalition } & Core & Shapley-value \\
\hline & Influence of all agents & \\
\hline \multirow[t]{2}{*}{ Coalition structure } & PCore & Aumann-Drèze-v. \\
\hline & outside option & no outside option \\
\hline \multirow[t]{2}{*}{ Restricted grand coalition } & Restricted core ("Network-Core") & Myerson-value \\
\hline & Influence of all agents & \\
\hline \multirow[t]{2}{*}{$\begin{array}{l}\text { Restricted coalition } \\
\text { structure }\end{array}$} & Restricted PCore & $\begin{array}{l}\text { Myerson-v. for coalition } \\
\text { structures }\end{array}$ \\
\hline & outside option & no outside-option \\
\hline
\end{tabular}

1. For the agents $A, B, C \in N$ : if $A$ has to select the cooperation partner and $v(A B)>$ $v(A C)$, then A selects $\mathrm{B}$ and first demands the amount: $v(A C)$ by agent $B$.

2. Afterwards the contributions are balanced:

$$
\begin{aligned}
& \operatorname{OOCS}_{A}(N, v, g)-\operatorname{OOCS}_{A}(N, v, g \backslash\{B\})= \\
& \operatorname{OOCS}_{B}(N, v, g)-\operatorname{OOCS}_{B}(N, v, g \backslash\{A\}) .
\end{aligned}
$$

So that $\mathrm{A}$ and $\mathrm{B}$ divide the difference of $B$ 's and $C$ 's offer equally.

For three agents the outside-option-modified allocation rule for coalition structures is as follows:

For $v(A B)>v(A C)$,

OOCS - value $=\left(\frac{v(A B)+v(A C)}{2} ; \frac{v(A B)-v(A C)}{2} ; 0\right)$.

\section{In comparison:}

$A D-M y S C-$ value $=\left(\frac{v(A B)}{2} ; \frac{v(A B)}{2} ; 0\right)$.

In Table 4 the proposed OOCS-value is compared with the AD-value (=Myerson-CSvalue) in dynamic setting where $\{A C\}$ increases continuously.

The figures $15 \mathrm{a}, 15 \mathrm{~b}$ and $15 \mathrm{c}$ depict a process where at the beginning the offer of $\mathrm{A}$ is better than that of B. However B continuously improves his offer. In $15 \mathrm{~b}$ they are identical and afterwards (15c) B's offer is better. The figures show the respective PCores (here: equal to the cores) the AD-values (=Myerson-CS-values) and in comparison the OOCS-values.

In these figures it is visible that the OOCS-value is always in the middle of that edgePCore (here equal to the core). In opposite the AD-value/Myerson-CS-value does not 
Table 4. Comparison of the AD-value (=Myerson-CS-value) with the proposed OOCS-value for non-balanced characteristic functions

\begin{tabular}{|c|c|c|c|c|}
\hline$v^{\{A B\}}$ & $v^{\{A C\}}$ & $\begin{array}{l}\text { Non-bal. if: } \\
v^{\{\{A B\}\{A C\}\}}<\end{array}$ & $\begin{array}{l}\text { AD-value = } \\
\text { MyCS-value }\end{array}$ & $\begin{array}{l}\text { proposed value } \\
\quad \text { (OOCS) }\end{array}$ \\
\hline 60 & 0 & 30 & $(30,30,0)$ & $(30,30,0)$ \\
\hline 60 & 10 & 35 & $(30,30,0)$ & $(35,25,0)$ \\
\hline 60 & 20 & 40 & $(30,30,0)$ & $(40,20,0)$ \\
\hline 60 & 30 & 45 & $(30,30,0)$ & $(45,15,0)$ \\
\hline 60 & 40 & 50 & $(30,30,0)$ & $(50,10,0)$ \\
\hline 60 & 50 & 55 & $(30,30,0)$ & $(55,5,0)$ \\
\hline 60 & 60 & 60 & $(30,30,0)$ or $(30,0,30)$ & $(60,0,0)$ \\
\hline 60 & 70 & 65 & $(35,0,35)$ & $(65,0,5)$ \\
\hline 60 & 80 & 70 & $(40,0,40)$ & $(70,0,10)$ \\
\hline 60 & 90 & 75 & $(45,0,45)$ & $(75,0,15)$ \\
\hline 60 & 100 & 80 & $(50,0,50)$ & $(80,0,20)$ \\
\hline
\end{tabular}

\begin{tabular}{|c|c|c|}
\hline & \multicolumn{2}{|c|}{ Coalition Values } \\
\hline & $A B$ & 20 \\
\hline & $A C$ & 15 \\
\hline & $B C$ & 0 \\
\hline & $A B C$ & 0 \\
\hline 00CS-value & \multicolumn{2}{|c|}{$A D$-value } \\
\hline Ie = Mlyerson-CS-value & $A$ & 10 \\
\hline$\lambda \quad{ }_{B}$ & $B$ & 10 \\
\hline Core = PCore & $c$ & 0 \\
\hline
\end{tabular}

Fig. 15a. Core, PCore, AD-value/MyCS-value and OOCS-value if B's proposal is higher than C's

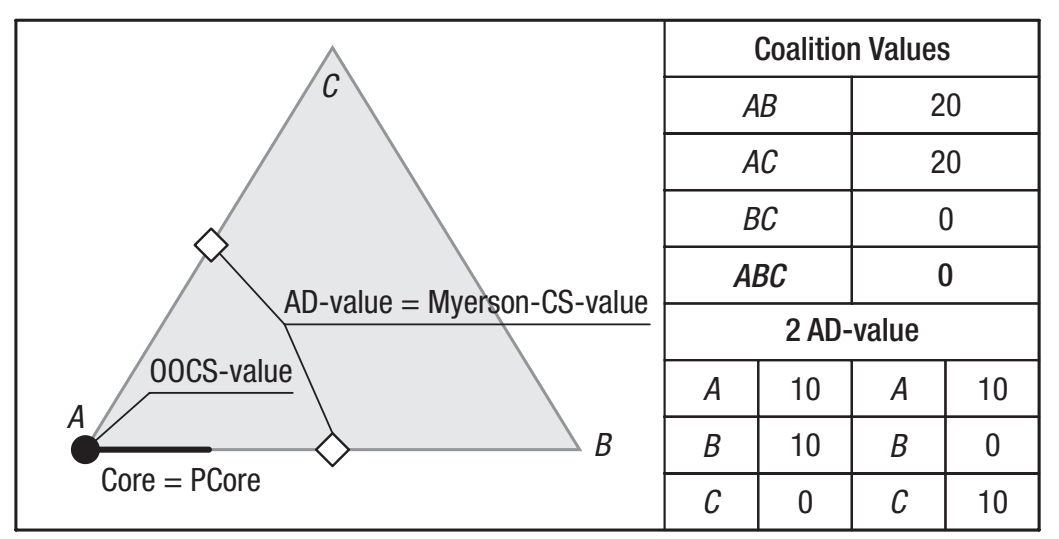

Fig. 15b. Core, PCore, AD-value/MyCS-value and OOCS-value if B's and C's proposals are equal 


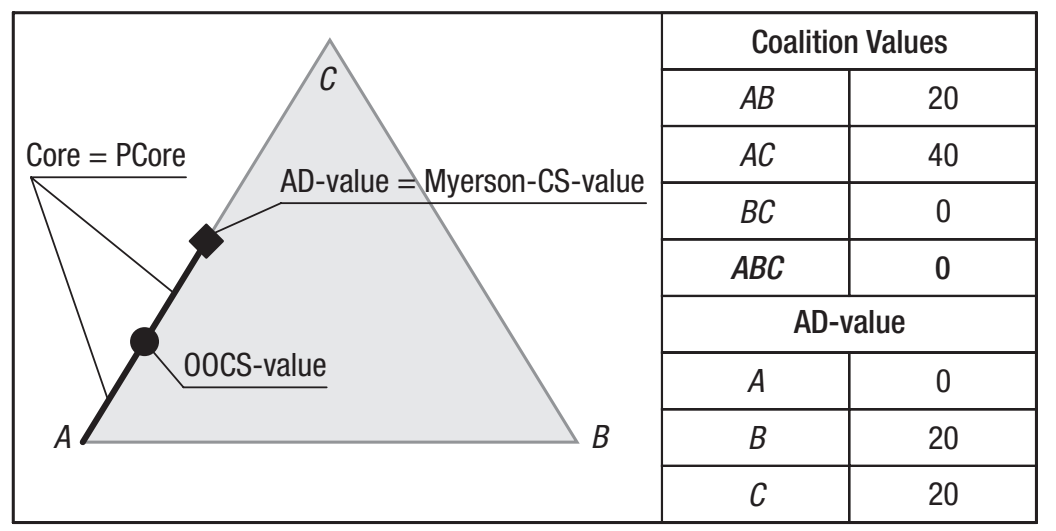

Fig. 15c. Core, PCore, AD-value/MyCS-value and OOCS-value after $\mathrm{C}$ has exceeded B's proposal

fulfil this property. This has the following implications (valid if the costs of switching or breaking the agreement are sufficiently low):

- An allocation in accordance with the OOCS-value does not depend on the bindingness of the agreement as it is a strong equilibrium and hence a CPNE.

- While an allocation agreement in accordance with the AD-value possibly (if it is not in the PCore or core) is broken immediately in dynamic setting, and OOCS-value based agreement remains stable as long as it remains in the PCore or core.

- Being a CPNE, and agreement based on the OOCS-value does not require the mutual assumption of others' rationality.

\section{Application of the introduced "OOCS-value" for enterprise cooperation in supply chains}

Finally the importance of the introduced allocation rule is demonstrated by the means of an application in a supply chain, where an enterprise (the demander $A$ ) is looking for the supplement of a certain good and has the choice between two or more candidates (the agents $B$ and $C$ ). Each relationship with a supplier is connected with transaction costs (e.g. administration cost). After "new institutional economics" each transaction is connected with costs and the transaction costs determine industrial structure (Williamson 1985). Here it assumed that the transaction costs increase with each additional supplier in a way that it is not worth to have more than one.

In game theory it can be depicted as a non-balanced restricted coalition game with 3 agents, where there is no link between the suppliers. The demander has to select a supplier. The other one is excluded and represents the outside option. The 2 cases are compared whether

- the switching costs for the demander are high (the agreement is binding) or

- the switching costs for the demander are sufficiently low (the agreement is not binding).

In the example, the (unbalanced) characteristic network function at the outset is ( $A$ is demander, $B$ is the stronger supplier and $C$ is the weaker supplier): 
$v_{g}=\left\{\begin{array}{l}0 ; \mid \text { agents } \mid \leq 1 \\ 60 ; g=\{A ; B\} \\ 40 ; g=\{A ; C\} \\ 45 ; g=\{A B, A C\} .\end{array}\right.$

After the supply chain cooperation has started, the supplier $C$ stepwise improves his offer so that the value of $g=\{A ; C\}$ increases from 40 to 120 . It is the 5-step sequence: $N G^{1}\left(N, v^{1}, g\right), \ldots, N G^{5}\left(N, v^{5}, g\right)$.

Figure 16 shows the process for the 2 cases of "high switching costs" and "low switching costs".

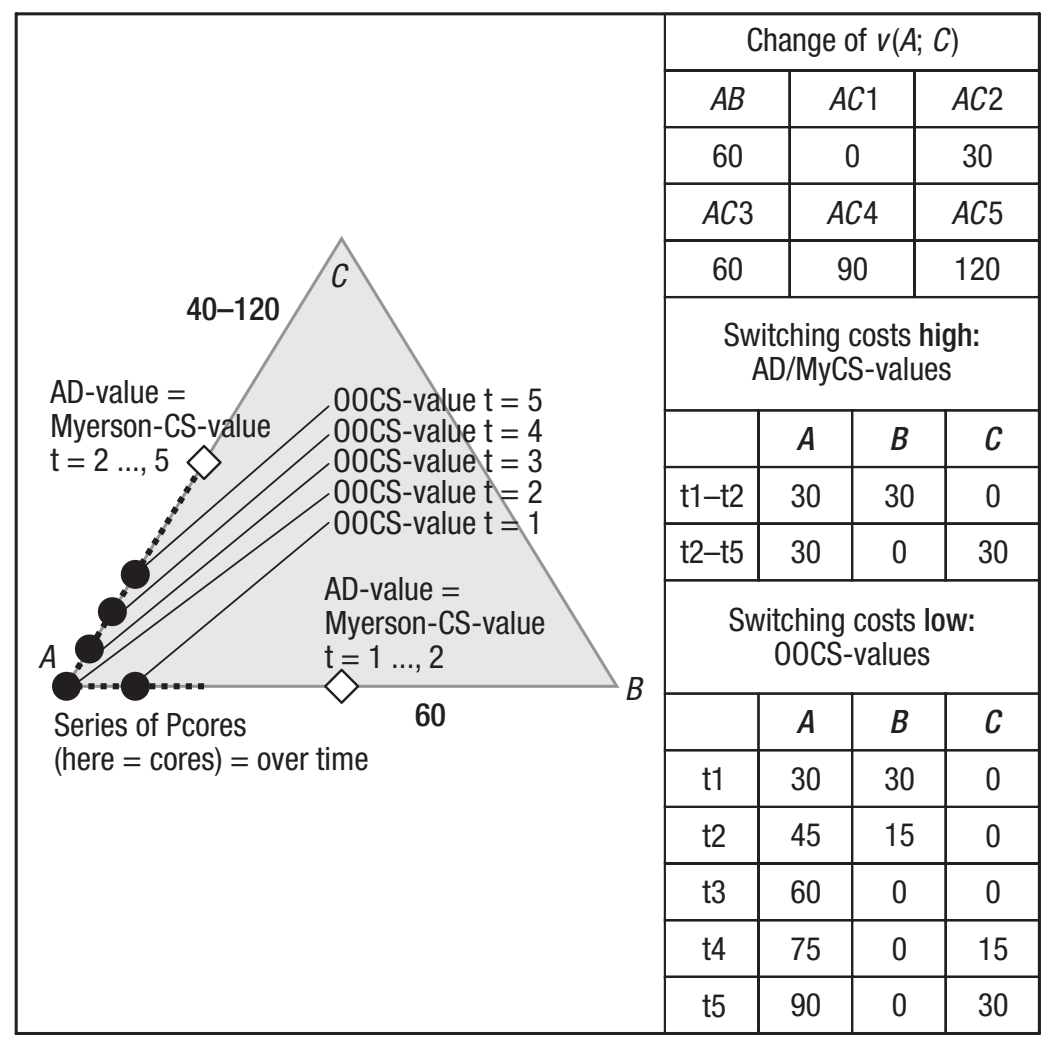

Fig. 16. Stability in dynamic supply chain cooperation, comparison of high and low switching costs

\section{High switching costs (agreement binding):}

The demander $A$ becomes unsatisfied with the agreement with $B$ due to the improved offers of agent $C$ (time-inconsistency). Nevertheless he cannot break the agreement advantageously. As $C$ leaves the bargaining table immediately, $A$ and $B$ share the profit equally due to Myerson's axiom of balanced contributions. Thus, the Aumann-Drèzevalue or the Myerson-value for coalition structures is deployed.

\section{Sufficiently low switching costs (agreement not binding):}

Each agreement that is not the PCore (here equal to the core), can be blocked by an alternative subgroup. The excluded agent $C$ remains at the bargaining table as the "outside option". Time-inconsistency steadily endangers the agreement. However "small 
changes" to not lead to a breach of contract as the allocation that is proposed by the OOCS-value in is the middle of the PCore (core). Thus, an agreement that follows the OOCS-value is not necessarily stable over the whole time of the cooperation. However being a coalition-proof Nash-equilibrium neither the bindingness of the agreement is required, nor that the agents mutually impute rationality.

\section{Conclusions}

\section{Fields of game theory:}

Basically, each game is strategic (non-cooperative), also the network and coalition games despite of a very different formalization. The network and coalition games (as a special case where the bilateral links are not restricted) investigate the stability of binding agreements. However the results of an underlying strategic game are implicit in the values of the characteristic functions. Thus, the relations between the fields of game theory are:

Strategic games $\supset$ network games $\supset$ coalition games

\section{Ubiquity of time-inconsistency of agreements:}

In dynamic models the preferences, the knowledge of the agents and the environmental parameters steadily change. Even if an agent intends to behave rationally, this is not perfectly achievable due to bounded rationality. Additionally the ability of contemplation can improve and new information can become available (learning process), or the opposite possibly takes place (obliviousness). All these aspects have the consequence that among the agents that have made an agreement there is at least one that becomes dissatisfied. This engangers the stability of the agreements but does not neccesarily lead to a breach as long as there is no better alternative.

\section{Coalition-proof Nash-equilibrium (CPNE):}

CPNE is a stability notion for coalition and network formation with 3 or more agents, if the bindingness of agreements is not required. The CPNE is more plausible and has less existence problems than Aumann's "strong equilibrium", due to the fact that it claims that a subgroup that wants to block the coalition/network formation, must not be blocked by another group (internal consistency). Additionally the CPNE is the sum of Pareto-efficiency and the "dominant equilibrium" (does not require the assumption of rationality of other agents). The investigation shows that (beyond the statement of Bernheim/Peleg) the CPNE is qualified as a standard criterion for stability in dynamic models with time-inconsistency.

\section{Peculiarity of core at the imputation set edge:}

The situation occurs that it does not matter whether a certain "third agent" (the agent of the opposite corner) participates in the agreement or not. This agent neither takes part in the profit division, nor he can block. An inofficial 2-agents-coalition forms, despite of the fact that the grand coalition "officially" exists and is stable. The excluded agent restricts the set of stable allocations and therefore is an outside option. Thus, for an allocation that is both in the core and at the edge of the imputation set, the grand coalition and the refering 2-agents-coalitions are equivalent. All stable 
2-agents-coalitions yield the PCore (generalization of the bargaining-set $\boldsymbol{M}$ ) at the edge of the imputation set.

\section{Advantages and disadvantages of network games:}

\section{Advantages:}

- Possibility to depict the relationships between the agents more precisely, restrictions in communication can be considered.

- Each bilateral link can be specified separately, a coalition game with $N$ agents consists of $\frac{N(N-1)}{2}$ links.

Disadvantages:

- Drastic increase of complexity (however still moderate with 3 agents).

- Limited applicability under consideration of bounds of human and maschine computability (complexity class NP-hard).

\section{Allocation rule with outside option:}

The Aumann-Drèze-value and the "Myerson-value for coalition structures" neglect the outside option. The outside option becomes relevant when an agent that is participating in the agreement, obtains the possibility to break the agreement and make a new agreement with an originally excluded agent advantagously. The proposed allocation rule considers:

- Component/Link-Pareto-efficiency.

- A modified Myerson-axiom of balanced contributions, where an auction is assumed where the winning bidder firstly pays the bid of the losing bidder, and the difference of the bids is shared after the balanced-contributions-axiom. Though it is comparable with the Vickrey-auction, it is assumed for simplicity that the auction giver is informed about the reservation prices of the bidders.

The allocation is stable against the deviations of subgroups of agents as it always lies in the PCore (e.g. bargaining set $\boldsymbol{M}$ ) and is a CPNE (no assumption of other agents' rationality).

7. Balancedness of the characteristic function as determinant of industrial structure: The balancedness of the characteristic function in games with transferable utility (TU-games) determines, whether a grand coalition or restricted grand coalition is stable against the blocking by subcoalitions/subnetworks. I.e. with 3 agents, the balancedness is the condition that a demander cooperates with both suppliers. In a nonbalanced characteristic function (that is investigated in the paper) he cooperates with maximally one. Non-balancedness is the prerequisite for the existence of excluded agents that are an outside option.

\section{Applicability in industrial cooperation relationships:}

In a dynamic model, in which a demander has the choice between two suppliers, and the characteristic function is non-balanced (demander selects exactly 1 supplier), it can be distinguished between:

- High costs of switching the cooperation partner: Aumann-Drèze-value and Myerson-value for coalition structures have the right properties and are stable.

- Low costs of switching the cooperation partner: proposed allocoation rule under consideration of outside option has the right properties and is stable. 


\section{References}

Arieli, D. 2008. Predictably irrational. $1^{\text {st }}$ edition. New York, NY: Harpercollins.

Aumann, R. J. 1959. Acceptable points in general cooperative n-person games, in Topics in Mathematical Economics and Game Theory. Providence, NY, American Mathematical Society, 1-30.

Aumann, R. J. 1961. The core of a cooperative game without side payments, Transactions of the American Mathematical Society 98(3): 539-552. doi:10.2307/1993348

Aumann, R. J.; Maschler, M. 1964. The bargaining set for cooperative games, Advances in Game Theory, Annals of Mathematics Studies 52: 446-476.

Aumann, R. J. 1970. Measurable utility and the measurable choice theorem, Collected Papers, Vol. 1, Cambridge, MA: The MIT Press, 279-290.

Aumann, R. J.; Drèze, J. 1975. Cooperative games with coalition structures, International Journal of Game Theory 3(4): 217-237. doi:10.1007/BF01766876

Aumann, R. J.; Myerson, R. B. 1988. Endogeneous formation of links between players and of coalitions: an application of the Shapley value, in A. E. Roth. The Shapley value - Essays in honor of Lloyd S. Shapley, Cambridge, UK: Cambridge University Press, 175-191.

Arrow, K. J. 1970. Social choice and individual values. $2^{\text {nd }}$ edition. New Haven, CT, USA: Yale University Press.

Bergstrom, T.; Varian, H. 1985. When do market games have transferable utility? Journal of Economic Theory 35(2): 222-233. doi:10.1016/0022-0531(85)90041-9

Bernheim, B.; Peleg, B. 1987. Coalition-Proof Nash-Equilibria, I.Concepts, Journal of Economic Theory 42(1): 1-12. doi:10.1016/0022-0531(87)90099-8

Bernheim, B.; Whinston, M. 1987. Coalition-Proof Nash-Equilibria, II. applications, Journal of Economic Theory 42(2): 13-29. doi:10.1016/0022-0531(87)90100-1

Bhattacharya, A. 2004. On the equal division core, Social Choice Welfare 22(1): 391-399. doi:10.1007/s00355-003-0221-2

Bilbao, J. M. 2000. Cooperative games on combinatorial structures. $2^{\text {nd }}$ edition. Berlin: Springer.

Binmore, K. 1994. Game theory and the social contract $i$, playing fair. $1^{\text {st }}$ edition. Cambridge, Massachusetts : The MIT Press.

Bondavera, O. N. 1963. Some applications of linear programming methods to the theory of cooperative games, Problemy Kibernetiki [Russian: Problems of Cybernetics] 10: 111-139.

Brauers, W. K. M.; Zavadskas, E. K. 2006. The MOORA method and its application to privatixation in a transition economy, Control and Cybernetics 35(2): 445-469.

Brauers, W. K. M.; Ginevičius, R.; Zavadskas, E. K.; Antuchevičienė, J. 2007. The European Union in a transition economy, Transformations in Business \& Economics 6(2): 21-37.

Casajus, A. 2007. Outside options, component efficiency, and stability, Games and Economic Behavior 65(1): 49-61. doi:10.1016/j.geb.2007.04.003

Casajus, A.; Tutic, A. 2007. On the partitional core, The International Journal of Game Theory [online]. University Leipzig [cited 30 Nov. 2009]. Available from Internet: <http://www.unileipzig.de/ micro/pcore.pdf $>$.

Chen, Y. 2006. Multiple criteria classification with an application in water resources planning, Computers and Operations Research 33(11): 3301-3323. doi:10.1016/j.cor.2005.03.026

Condorcet, M. 1785. Essai sur l'application del'analyse à la probabilité des décisions rendues à la pluralité des voix [French: Essay of the application of the analysis of decision probabilities with more than one vote], Paris: l'imprimerie royale.

Davis, M.; Maschler, M. 1962. Existence of stable payoff configurations for cooperative games, Bulletin of the American Mathematical Society 69: 106-108.

doi:10.1090/S0002-9904-1963-10879-4 
Demange, G.; Wooders, M. 2005. Group formation in economics - networks, clubs and coalitions. $1^{\text {st }}$ edition. Cambridge, UK: Cambridge University Press.

Dutta, B.; Ghosal, S.; Ray, D. 2004. Farsighted network formation, Journal of Economic Theory 122(2): 143-164. doi:10.1016/j.jet.2004.05.001

Figuera, J.; Greco, S. 2005. Multiple Criteria Decision Analysis. $1^{\text {st }}$ edition. Berlin: Springer.

Friedman, M. 1966. The methodology of positive economics in Essays in Positive Economics, Chicago, USA: University of Chicago Press, 3-45.

Ginevičius, R.; Krivka, A. 2008. Application of game theory for duopoly market analysis, Journal of Business Economics and Management 9(3): 207-217. doi:10.3846/1611-1699.2008.9.207-217

Ginevičius, R.; Podvezko, V. 2008a. Multicriteria graphical-analytical evaluation of the financial state of construction enterprises, Technological and Economic Development of Economy 14(4): 452-461. doi:10.3846/1392-8619.2008.14.452-461

Ginevičius, R.; Podvezko, V. 2008b. Multicriteria evaluation of Lithuanian banks from the perspective of their reliability for clients, Journal of Business Economics and Management 9(4): 257-267. doi:10.3846/1611-1699.2008.9.257-267

Ginevičius, R.; Podvezko, V. 2009. Evaluating the changes in economic and social development of Lithuanian counties by multiple criteria methods, Technological and Economic Development of Economy 15(3): 418-436. doi:10.3846/1392-8619.2009.15.418-436

Ginevičius, R.; Zubrecovas, V. 2009. Selection of the optimal real estate investment project basing on multiple criteria evaluation using stochastic dimensions, Journal of Business Economics and Management 10(3): 261-270. doi:10.3846/1611-1699.2009.10.261-270

Ginevičius, R.; Butkevičius, A.; Podvezko, V. 2006. Complex evaluation of economic development of the Baltic States and Poland, Ekonomický Casopis 54(9): 918-930.

Ginevicius, R.; Podvezko, V.; Andruskevicius, A. 2007. Quantitative evaluation of building technology, International Journal of Technology Management 40(1-3): 192-214.

doi:10.1504/IJTM.2007.013534

Ginevičius, R.; Podvezko, V.; Bruzgè, Š. 2008a. Evaluating the effect of state aid to business by multicriteria methods, Journal of Business Economics and Management 9(3): 167-180. doi:10.3846/1611-1699.2008.9.167-180

Ginevičius, R.; Podvezko, V.; Raslanas, S. 2008b. Evaluating the alternative solutions of wall insulation by multicriteria methods, Journal of Civil Engineering and Management 14(4): 217-226. doi:10.3846/1392-3730.2008.14.20

Güth, W. 2007. Theorie der marktwirtschaft [Theory of market economy]. $2^{\text {nd }}$ edition. Berlin: Springer.

Harsanyi, J. C. 1967. Games with incomplete information, Management Science 14(3): 159-182. doi:10.1287/mnsc.14.3.159

Harsanyi, J. C. 1977. Rational behavior and bargaining equilibrium in games and social situations. $1^{\text {st }}$ edition. Cambridge, UK: Cambridge University Press. doi:10.1017/CBO9780511571756

Harsanyi, J. C.; Selten, R. 1988. A general theory of equilibrium selection in games. $1^{\text {st }}$ edition. Cambridge, Massachusetts : The MIT Press.

Hart, S.; Kurz, M. 1983. Endogenous formation of coalitions, Econometrica 51(4): 1047-1064. doi: $10.2307 / 1912051$

Hellman, Z. 2008. Bargaining set solution concepts in dynamic cooperative games. Munich Personal RePEc Archive [online] [cited 30 Nov. 2009]. Available from Internet: <http://comecon. eco.auckland.ac.nz/ppcgt/PPCGT_Papers/001-Hellman.pdf>.

Holler, M.; Illing, G. 2000. Einführung in die spieltheorie [Introduction into game theory]. 4. edition. Berlin: Springer. 
Holler, M.; Owen, G. 2001. Power indices and coalition formation. $1^{\text {st }}$ edition. Norwell, MA: Kluwer Academic Publishers.

Jackson, M. 2003a. Allocation rules for network games, Games and Economic Behavior 51(1): 128-154. doi:10.1016/j.geb.2004.04.009

Jackson, M. 2003b. A Survey of models of network formation: stability and efficiency, in Group Formation in Economics: Networks, Clubs, and Coalitions. Edited by Gabrielle Demange and Myrna Wooders. Cambridge, UK: Cambridge University Press, 11-57.

Jackson, M.; Nouweland, A. 2003. Strongly stable networks, Games and Economic Behavior 51(2): 420-444. doi:10.1016/j.geb.2004.08.004

Jain, K.; Vohra, R. 2006. On stability of the core, Microsoft Research and Department of Managerial Economics and Decision Sciences [online]. Evanston IL, USA : Northwestern University. [cited 30 Nov. 2009]. Available from Internet: <http:/www.kellogg.northwestern.edu/faculty/ vohra/ftp/newcore.pdf $>$.

Jakimavičius, M.; Burinskienė, M. 2009a. Assessment of Vilnius city development scenarios based on transport system modelling and multicriteria analysis, Journal of Civil Engineering and Management 15(4): 361-368. doi:10.3846/1392-3730.2009.15.361-368

Jakimavičius, M.; Burinskienè, M. 2009b. A GIS and multi-criteria-based analysis and ranking of transportation zones of Vilnius city, Technological and Economic Development of Economy 15(1): 39-48. doi:10.3846/1392-8619.2009.15.39-48

Joshi, S. 2006. Endogenous formation of coalitions in a model of a race, Journal of Economic Behavior \& Organization 65(1): 62-85. doi:10.1016/j.jebo.2005.09.004

Kahan, J.; Rapoport, A. 1984. Theories of coalition formation. $1^{\text {st }}$ edition. Philadelphia, PA: Lawrence Erlbaum Associates.

Kahneman, D.; Tversky, A. 1979. Prospect theory: An analysis of decision under risk, Econometrica 47(2): 263-291. doi:10.2307/1914185

Kajii, A.; Kojima, H.; Ui, T. 2008. The Myerson value for complete coalition systems. Faculty of Economics, Yokohama National University. Available from Internet: <http://www2.igss.ynu. ac.jp/ oui/netgame.pdf>.

Kranich, L.; Perea, A.; Peters, H. 2005. Core concepts for dynamic TU games, International Game Theory Review 7(1): 43-61. doi:10.1142/S0219198905000417

Kuhn, H. W. 1953. Extensive games and the problem of information, in Kuhn, H. W. Classics in Game Theory. New Jersey, USA: Princeton University press, 48-68.

Kukitani, S. 1941. A generalization of Brouwer's fixed point theorem, Duke Mathematical Journal 150(3): 457-459. doi:10.1215/S0012-7094-41-00838-4

Liaudanskiene, R.; Ustinovicius, L.; Bogdanovicius, A. 2009. Evaluation of construction process safety solutions using the TOPSIS method, Inzinerine Ekonomika - Engineering Economics 4: $32-40$.

Liu, P. 2009. Multi-attribute decision-making method research based on interval vague set and TOPSIS method, Technological and Economic Development of Economy 15(3): 453-463. doi:10.3846/1392-8619.2009.15.453-463

Mitkus, S.; Trinkūniene, E. 2008. Reasoned decisions in construction contracts evaluation, Technological and Economic Development of Economy 14(3): 402-416.

doi:10.3846/1392-8619.2008.14.402-416

Moldovanu, B. 1992. Coalition-proof nash equilibria and the core in three-player games, Games and Economic Behavior 4(1): 565-581. doi:10.1016/0899-8256(92)90037-S

Moreno, D.; Wooders, J. 1996. Coalition-Proof equilibrium, Games and Economic Behavior 17(1): 80-112. doi:10.1006/game.1996.0095

Myerson, R. B. 1976. Graphs and cooperation in games, Mathematics of Operations Research 2(3): 225-241. doi:10.1287/moor.2.3.225 
Myerson, R. B. 1980. Conference structures and fair allocation rules, International Journal of Game Theory 9(3): 169-182. doi:10.1007/BF01781371

Navarro, N.; Perea, A. 2005. Bargaining in networks and the Myerson Value. UC3M Working Paper, Economics [online]. [Cited 30 Nov. 2009]. Available from Internet: <http://www.personeel.unimaas.nl/A.Perea/Papers/Myerson-June05.pdf $>$.

Nisan, N.; Roughgarden, T. 2007. Algorithmic game theory. $1^{\text {st }}$ edition. Cambridge, UK: Cambridge University Press.

Nouweland, A. 2003. Models of network formation in cooperative games, in Gabrielle Demange and Myrna Wooders, Group Formation in Economics: Networks, Clubs, and Coalitions, Cambridge, UK: Cambridge University Press, 58-88.

Peldschus, F. 2008. Experience of the game theory application in construction management, Technological and Economic Development of Economy 14(4): 531-545. doi:10.3846/1392-8619.2008.14.531-545

Peldschus, F. 2009. The analysis of the quality of the results obtained with the methods of multi-criteria decisions, Technological and Economic Development of Economy 15(4): 580-592. doi:10.3846/1392-8619.2009.15.580-592

Peldschus, F.; Zavadskas, E. K. 2005. Fuzzy matrix games multi-criteria model for decisionmaking in engineering, Informatica 16(1):107-120.

Peleg, B.; Sudhölter, P. 2003. Introduction to the theory of cooperative games. $1^{\text {st }}$ edition. Berlin: Springer.

Pin, P. 2005. A model of Myerson-Nash equilibria in networks, Lecture Notes in Economics and Mathematical Systems 564: 175-188. doi:10.1007/3-540-28547-4_15

Plebankiewicz, E. 2009. Contractor prequalification model using fuzzy sets, Journal of Civil Engineering and Management 15(4): 377-385. doi:10.3846/1392-3730.2009.15.377-385

Podvezko, V. 2008. Game theory in building technology and management, Journal of Business Economics and Management 9(3): 237-239. doi:10.3846/1611-1699.2008.9.237-239

Podvezko, V. 2009. Application of AHP technique, Journal of Business Economics and Management 10(2): 181-189. doi:10.3846/1611-1699.2009.10.181-189

Ray, D. 2007. A Game-Theoretic perspective on coalition formation. $1^{\text {st }}$ edition. Oxford, UK: Oxford University Press. doi:10.1093/acprof:oso/9780199207954.001.0001

Rubinstein, A. 1998. Modeling bounded rationality. $1^{\text {st }}$ edition. Cambridge, MA: MIT Press.

Shapley, L. S. 1953. A value for n-person games, in A. E. Roth. The Shapley value - Essays in honor of Lloyd S. Shapley. Cambridge, UK: Cambridge University Press, 31-40.

Shapley, L. S. 1967. On balanced sets and cores, Naval Research Logistics Quarterly 14(1967): 453-460. doi:10.1002/nav.3800140404

Shapley, L. S. 1971. Cores of convex games, International Journal of Game Theory 1(1): 11-26. doi:10.1007/BF01753431

Simon, H. 1994. The sciences of the artificial. $3^{\text {rd }}$ edition. Cambridge, MA: The MIT Press.

Sivilevičius, H.; Zavadskas, E. K.; Turskis, Z. 2008. Quality attributes and complex assessment methodology of the asphalt mixing plant, The Baltic Journal of Road and Bridge Engineering 3(3): 161-166. doi:10.3846/1822-427X.2008.3.161-166

Sobotka, A.; Rolak, Z. 2009. Multi-attribute analysis for the eco-energetic assessment of the building life cycle, Technological and Economic Development of Economy 15(4): 593-611. doi:10.3846/1392-8619.2009.15.593-611

Srnka, K.; Koeszegi, S. 2007. From Words to Numbers: How to transform qualitative data into meaningful quantitative results, Schmalenbach Business Review 59(1): 29-57.

Stanford Encyclopedia of Philosophy, Aristotle's Ethics. 2007. [online] [accessed 28 Nov. 2009] Available from Internet: <http://plato.stanford.edu/entries/aristotle-ethics/\#DifAffPla>. 
Steimle, J. 2008. Algorithmic mechanisn design. $1^{\text {st }}$ edition. Berlin: Springer.

Sun, N.; Trockel, W.; Yang, Z. 2008. Competitive outcomes and endogenous formation in an n-Person game, Journal of Mathematical Economics 44(7-8): 853-860.

doi:10.1016/j.jmateco.2007.03.002

Šelih, J.; Kne, A.; Srdić, A.; Žura, M. 2008. Multiple-criteria decision support system in highway infrastructure management, Transport 23(4): 299-305. doi:10.3846/1648-4142.2008.23.299-305

Šijanec Zavrl, M.; Žarnić, R.; Šelih, J. 2009. Multicriterial sustainability assessment of residential buildings, Technological and Economic Development of Economy 15(4): 612-630.

doi:10.3846/1392-8619.2009.15.612-630

Topkis, D. 1998. Supermodularity and complementarity. $1^{\text {st }}$ edition. New Jersey: Princeton University Press.

Turskis, Z.; Zavadskas, E. K.; Peldschus, F. 2009. Multi-criteria optimization system for decision making in construction design and management, Inzinerine ekonomika - Engineering Economics 1(61): 7-17.

Ulubeyli, S.; Kazaz, A. 2009. A Multiple criteria decision-making approach to the selection of concrete pumps, Journal of Civil Engineering and Management 15(4): 369-376.

doi:10.3846/1392-3730.2009.15.369-376

Ustinovichius, L.; Podvezko, V.; Ginevicius, R. 2006. A method of determining risk zones of investment in real estate, Control and Cybernetics 35(2): 471-486.

Vega-Redondo, F. 2003. Economics and the theory of games. $1^{\text {st }}$ edition. Cambridge, UK: Cambridge University Press.

Von Neumann, J.; Morgenstern, O. 2007. Theory of games and economic behaviour, 60. anniversary edition. New Jersey: Princeton University Press.

Vickrey, W. 1961. Counterspeculations, auctions, and competitive sealed tenders, Journal of Finance 16(1): 8-37. doi:10.2307/2977633

Wiese, H. 2005. Kooperative spieltheorie [Cooperative game theory]. $1^{\text {st }}$ edition. München: Oldenbourg Wissenschaftsverlag GmbH.

Williamson, O. E. 1985. The Economic institutions of capitalism. $1^{\text {st }}$ edition. New York, NY: The Free press.

Winter, E. 2001. Shapley value [online]. Hebrew University Jerusalem, Israel [cited 30 Nov. 2009]. Available from Internet: <http://www.ma.huji.ac.il/ mseyal/shapley4to95.pdf $>$.

Zavadskas, E. K.; Turskis, Z. 2008. A new logarithmic normalization method in games theory, Informatica 19(2): 303-314.

Zavadskas, E. K.; Vaidogas, E. R. 2008. Bayesian reasoning in managerial decisions on the choice of equipment for prevention of industrial accidents, Inzinerine Ekonomika - Engineering Economics 5(60): 32-40.

Zavadskas, E. K.; Kaklauskas, A.; Turskis, Z.; Tamošaitiene, J. 2008a. Selection of the effective dwelling house walls by applying attributes values determined at intervals, Journal of Civil Engineering and Management 14(2): 85-93. doi:10.3846/1392-3730.2008.14.3

Zavadskas, E. K.; Turskis, Z.; Tamošaitienè, J. 2008b. Contractor selection of construction in a competitive environment, Journal of Business Economics and Management 9(3): 181-187. doi:10.3846/1611-1699.2008.9.181-187

Zavadskas, E. K.; Andriuskevicius, A.; Podvezko, V. 2009. Quantitative evaluation of the organisation of manufacturing and technological processes, International Journal of Technology Management 48(4): 544-556. doi:10.1504/IJTM.2009.026693

Zhao, J. 2008. The core and coalition formation in an n-person network game [online]. University of Saskatchewan, Canada [cited 30 Nov. 2009]. Available from Internet: <http://homepage. usask.ca/ jiz400/wp/cng.pdf $>$. 


\section{AGENTŲ SUSITARIMAI ŽAIDIMŲ TEORIJOJE ESANT PAPILDOMŲ ALTERNATYVU GALIMYBEI NESUDERINTAME LAIKE}

\section{H. D. Stein}

Santrauka

Žaidimų teorijoje agentai turi galimybę sudaryti įsipareigojančius susitarimus. Agentai, kaip yra manoma, numato savo strategijas riboto racionalumo sąlygomis. Strateginių žaidimų sritis sudaro galimybę agentui suvokti optimalios elgsenos krypti. Straipsnyje tyrinejjamas ryšys tarp skirtingų žaidimų teorijos sričių tuo atveju, kai susitarimuose dalyvauja trys agentai. Atskleidžiamas neišvengiamas agentų elgsenos nesuderinamumas dèl riboto racionalumo, apgavysčiu bei aplinkos pokyčių. Straipsnyje aiškinama, kad žaidimų teorijos numatomos agentų susitarimų taisyklès turètų būti modifikuotos siekiant ivvertinti papildomų susitarimų alternatyvų galimybę.

Reikšminiai žodžiai: susitarimai žaidimų teorijoje, tinklų žaidimai, susitarimų taisyklès, nesuderintas laikas, papildoma alternatyva.

Harald David STEIN is a Ph.D. student at the Faculty of Business Management at Vilnius Gediminas Technical University. He received his Diploma in Business Administration (Betriebswirtschaftslehre) at Humboldt-University in Berlin, Germany in 2006. The main subjects have been Business Informatics, Econometrics and International Management. His major research fields are the ambivalence of competition and cooperation (co-opetition) in business relationships and the implementation of microeconomic or game theoretic tool on referring problems. Furthermore, he has made research on future mobile Internet markets and the co-opetition of providers of different mobile access technologies. Currently, he works on the accomplishment of his Ph.D. thesis. 